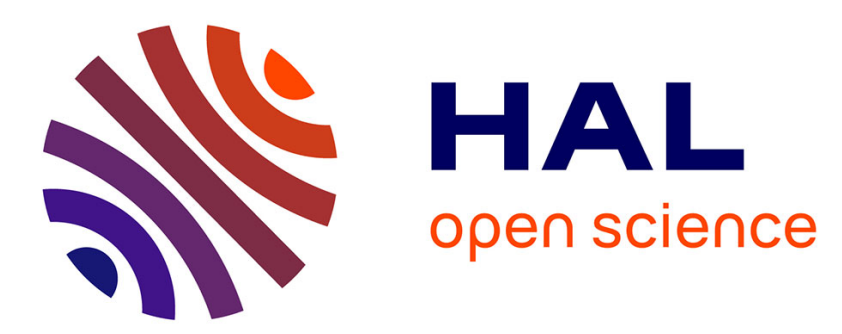

\title{
Effects of Fe competition on REE binding to humic acid: Origin of REE pattern variability in organic waters
} Remi Marsac, Mélanie Davranche, Gérard Gruau, Aline Dia, Mathieu Pédrot, Martine Bouhnik-Le Coz, Nicolas Briant

\section{- To cite this version:}

Remi Marsac, Mélanie Davranche, Gérard Gruau, Aline Dia, Mathieu Pédrot, et al.. Effects of Fe competition on REE binding to humic acid: Origin of REE pattern variability in organic waters. Chemical Geology, 2013, 342, pp.119-127. 10.1016/j.chemgeo.2013.01.020 . insu-00811470

HAL Id: insu-00811470 https://hal-insu.archives-ouvertes.fr/insu-00811470

Submitted on 10 Apr 2013

HAL is a multi-disciplinary open access archive for the deposit and dissemination of scientific research documents, whether they are published or not. The documents may come from teaching and research institutions in France or abroad, or from public or private research centers.
L'archive ouverte pluridisciplinaire HAL, est destinée au dépôt et à la diffusion de documents scientifiques de niveau recherche, publiés ou non, émanant des établissements d'enseignement et de recherche français ou étrangers, des laboratoires publics ou privés. 
Effects of Fe competition on REE binding to humic acid: origin of REE pattern variability in organic waters

Rémi Marsac, Mélanie Davranche*, Gérard Gruau, Aline Dia, Mathieu Pédrot, Martine Le Coz-Bouhnik and Nicolas Briant

Géosciences Rennes, UMR 6118 CNRS - Université Rennes 1, Campus Beaulieu, 35042 Rennes Cedex, France

*Corresponding author: Tel+33223235 769; Fax: +33223236090

E-mail address: melanie.davranche@univ-rennes1.fr 
Abstract- Competitive mechanisms between rare earth elements (REE) and iron (Fe) for humic acid (HA) binding were investigated by coupling laboratory experiments and modeling calculations using PHREEQC/Model VI. This study aims, firstly, at determining the effect of Fe on REE-HA binding, in order to explain the REE pattern variability observed in natural organic-rich waters. Secondly, it has previously been shown that light and heavy REE (L- and HREE) speciation with HA molecules differ with $\mathrm{pH}$. Therefore, REE-HA complexation patterns have been used as a probe of Fe-HA binding mechanisms. At $\mathrm{pH}$ 3, i.e. $\mathrm{pH}$ conditions at which $\mathrm{Fe}^{3+}$ binds to $\mathrm{HA}, \mathrm{Fe}$ is shown to be a strong competitor for heavy REE (HREE), suggesting that $\mathrm{Fe}^{3+}$ has a marked affinity for the few strong HA multidentate sites. At $\mathrm{pH}$, i.e. under $\mathrm{pH}$ conditions at which hydrolyzed Fe species bind to HA, Fe appears to compete equally for every REE, thereby indicating that Fe has the same relative affinity for carboxylic and phenolic HA sites as LREE and HREE, respectively. Fractionation of REE in organicrich naturals waters depends mainly on the coupling of two factors: (i) the total dissolved metals concentration (i.e. the HA metal loading) and (ii) the competition between REE and major cations (i.e. $\mathrm{Fe}$ and $\mathrm{Al}$ ). The $\mathrm{pH}$, which regulates the speciation of these competitive metals, is, therefore, indirectly the main controlling factor of REE fractionation in organicrich waters.

Keywords: rare earth elements, iron, competition, complexation, humic acid, PHREEQC, Model VI.

\section{Introduction}

Organic colloids such as humic acids (HA) are ubiquitous in natural waters and present a high binding capacity for dissolved metals. Over the past two decades, remarkable efforts have 
been made to clarify the processes involved in metal binding by $\mathrm{HA}$, through both experimental and modeling approaches (e.g. Tipping, 1998; Milne et al., 2003 and references therein). However, the exact nature of the processes involved is still not fully understood, mainly because of the complex structure of HA, and notably the heterogeneity of the HA binding sites. Rare earth elements (REE) are a group of fourteen elements presenting very similar and coherent chemical properties. Plots of REE concentrations in natural systems versus atomic number (the so called REE pattern) are commonly used as hydrological and geochemical tracers (Henderson, 1984). REE patterns can also be described by the partition coefficients between two phases $\left(\mathrm{K}_{\mathrm{d}}^{\mathrm{REE}}\right)$. Thanks to unique chemical properties of REE, their partition coefficients between $\mathrm{HA}$ and aqueous solution are highly sensitive to the heterogeneity of HA binding sites. As shown by recent studies (Sonke and Salters, 2006; Marsac et al., 2010; Yamamoto et al., 2010), specific $\mathrm{K}_{\mathrm{d}}{ }^{\mathrm{REE}}$ patterns arise depending on the nature of the major HA binding sites for REE. For example, $\log \mathrm{K}_{\mathrm{d}}{ }^{\mathrm{REE}}$ patterns can exhibit a progressive enrichment from light REE (LREE) to heavy REE (HREE) in HA-suspensions at low REE to HA concentration ratios. This pattern is expected to correspond to the binding of REE to the few strong multidentate sites (Sonke and Salters, 2006; Marsac et al., 2010; Yamamoto et al., 2010). By contrast, the characteristic middle REE (MREE) enrichment displayed by the $\log \mathrm{K}_{\mathrm{d}}{ }^{\mathrm{REE}}$ patterns for acidic $(\mathrm{pH}=3)$ and high REE/HA has been shown to be produced by the binding of REE to the abundant weak carboxylic sites (Tang and Johannesson 2003; Pourret et al., 2007b).

The ability of the $\log \mathrm{K}_{\mathrm{d}}^{\mathrm{REE}}$ patterns to elucidate the REE-HA binding processes has been recently improved by a modeling study using the new coupled program PHREEQC/Model VI (Marsac et al., 2011). Our previous study showed that the binding process involved in the MREE enrichment development for high REE/HA and high $\mathrm{pH}(\mathrm{pH}=6)$ was different from that developed for $\mathrm{pH}=3$ conditions, as LREE and HREE were bound to different HA sites. 
More specifically, LREE are mainly bound by weak HA carboxylic sites at pHs ranging between 3 and 6, although HREE are preferentially bound to strong multidentate sites at $\mathrm{pH}=$ 3 and to phenolic groups at $\mathrm{pH}=6$. The variation in the $\log \mathrm{K}_{\mathrm{d}}^{\mathrm{REE}}$ pattern has recently led to the use of REE as a "probe" to determine the processes of trace metal binding to HA (Marsac et al., 2012). All trace metals able to bind more strongly than REE to specific HA sites will modify the $\log \mathrm{K}_{\mathrm{d}}{ }^{\mathrm{REE}}$ pattern. In turn, the evolution of the $\log \mathrm{K}_{\mathrm{d}}^{\mathrm{REE}}$ pattern provides information on the HA sites involved in dissolved metal-HA binding. Marsac et al. (2012) have already used this "REE probe" in a study dedicated to the competitive effects of $\mathrm{Al}$ on REE binding to HA. They showed that $\mathrm{Al}\left(\mathrm{Al}^{3+}\right)$ was dominantly bound to strong HA multidentate sites at low $\mathrm{REE} / \mathrm{HA}$ and $\mathrm{pH}=3$ conditions (based on stronger competition with HREE than LREE), but that most of the Al (hydroxy-Al species) was bound to the weaker carboxylic sites under high $\mathrm{REE} / \mathrm{HA}$ and $\mathrm{pH}=6$ conditions (based on stronger competition with LREE than HREE).

Another issue of the studies dedicated to metal-REE competition for HA binding concerns the origin and significance of the REE pattern variability in natural, organic-rich waters. There is now ample evidence that HA controls REE speciation in natural organic-rich waters and that nearly $100 \%$ of REE occur as organic complexes in these waters (e.g. Takahashi et al., 1997; Viers et al., 1997; Dia et al., 2000; Gruau et al., 2004; Tang and Johannesson, 2003; Johannesson et al., 2004; Pourret et al., 2007a,b; 2010). Yet, REE patterns are highly variable in these waters; neutral to alkaline waters present continuously enriched REE patterns from La to Lu, whereas acidic ones exhibit marked MREE enrichment (Elderfield et al., 1990). This variability was initially attributed, from neutral to high $\mathrm{pH}$, to the complexation of REE with carbonates, because carbonates have higher affinity for HREE (Luo and Byrne, 2004) and, at low pH, to REE-HA binding, because HA have higher affinity for MREE (Sonke and Salters, 2006). The recent REE-HA binding studies and evidence of the control of the REE 
speciation by organic colloids raise the possibility that the variations in REE patterns could be due to changes at the REE-HA binding sites. HA could enhance MREE or HREE solubility depending on the physico-chemical conditions. These changes could be themselves induced by the binding of metals that compete with REE for the same HA sites.

Despite the low solubility of Fe (hydr)oxides, high Fe concentrations can be found in organicrich waters, associated with organic colloids (Olivié-Lauquet et al. 1999; Allard et al. 2004; Pokrovsky et al., 2005; Pédrot et al., 2011). Dissolved organic matter (DOM) inhibits the crystallization of Fe (hydr)oxides, forming both Fe nano-(hydr)oxides coated with DOM and Fe(III)-DOM complexes instead (e.g. Pédrot et al., 2011). Therefore, Fe, like Al, is expected to strongly influence REE speciation in organic waters (Tanizaki et al., 1992; Tang and Johannesson, 2003; Lippold et al., 2007). As shown by recent spectroscopic studies, Fe binds to $\mathrm{HA}$ as Fe polynuclear species under high Fe/HA conditions, whereas monomeric Fe-HA complexes are formed under low Fe/HA conditions (Vilgé-Ritter et al., 1999; Karlsson and Persson, 2010). Using the Stockholm Humic Model (SHM), Gustafsson et al. (2007) satisfactorily simulated Fe binding to soil organic matter (SOM) and its competitive effects on various metals. However, in their modeling approach, Gustafsson and coworkers only took into account that Fe dimers can be bound to SOM tridentate sites. Model VI (Tipping, 1998), a specific model for metal binding by $\mathrm{HA}$, only considers the binding of $\mathrm{Fe}^{3+}$ and $\mathrm{FeOH}^{2+}$ to HA, and not the possible binding of Fe polymers. Therefore, none of these models includes either the polynuclear Fe-HA complexes, recently highlighted by spectroscopic data, or the formation of Fe mononuclear complexes with HA.

This study aimed at assessing the competitive effects of Fe on REE binding to HA in order to (i) determine whether Fe can influence REE patterns in natural waters and (ii) to test the ability of the "REE probe" to identify the HA sites and mechanisms involved in the binding of Fe to HA. For this purpose, REE-Fe-HA binding experiments were performed using fourteen 
$\mathrm{REE}$ and $\mathrm{Fe}$, over a $\mathrm{pH}$ range from 3 to 6 . The experimental data were subsequently modeled using PHREEQC/Model VI. The speciation results for Fe were compared with recently published spectroscopic data to assess the consistency of the model. Finally, the REE patterns of a large set of natural organic-rich waters were compared with the results of the present study as well as our previous study dealing with Al-REE competition (Marsac et al., 2012). This comparison allowed us to determine whether dissolved metal competition might account for the REE pattern variability observed in natural, organic-rich waters.

\section{Material and Methods}

\subsection{Experimental reagents}

All chemicals used were of analytical grade. All experimental solutions were prepared with doubly-deionized water (Milli-Q system, Millipore ${ }^{\mathrm{TM}}$ ). Synthetic REE and Fe solutions were prepared from a nitrate REE and Fe standard (10 $\mathrm{mg} \mathrm{L}^{-1}$, Accu Trace ${ }^{\mathrm{TM}}$ Reference Standard). Polyethylene containers used to reach complexation equilibrium were all previously soaked in $10 \%$ Ultrapure $\mathrm{HNO}_{3}$ for $48 \mathrm{~h}$ at $60^{\circ} \mathrm{C}$, then rinsed with deionized water for $24 \mathrm{~h}$ at $60^{\circ} \mathrm{C}$ to remove all REE contamination sources. All experiments were performed at room temperature, i.e. $20^{\circ} \mathrm{C} \pm 2$.

Purified humic acid (HA) was obtained from synthetic Aldrich humic acid (Aldrich ${ }^{\mathrm{TM}}, \mathrm{H} 1$, 675-2). The purification was performed using the Vermeer et al. (1998) protocol, except that a tangential ultrafiltration step was added to remove any possible HA molecules $<10 \mathrm{kDa}$ using a Labscale TFF system equipped with a Pellicon XL membrane (PLCGC10, Millipore ${ }^{\mathrm{TM}}$ ). Humic acid was freeze-dried and stored in a glass container. Prior to use, purified HA was solubilized overnight in a solution of $0.01 \mathrm{M} \mathrm{NaCl}$ at $\mathrm{pH}=10$ to ensure complete dissolution (Vermeer et al., 1998). The $\mathrm{pH}$ was adjusted to 3 in the HA suspensions using $0.1 \mathrm{M} \mathrm{HCl}$. The suspension was then filtered at $0.2 \mu \mathrm{m}$ to remove any potential precipitate and to ensure 
that the same HA fraction was studied in all experiments. The dissolved organic carbon (DOC) concentration of the filtrates was then measured to assess the true HA concentration of the experimental suspensions.

\subsection{Experimental set-up}

The competition effects of Fe on the REE binding by HA were experimentally investigated using a standard batch equilibrium technique. The experimental conditions (i.e. $\mathrm{pH}$; REE, Fe and HA concentrations; ionic strength) were adapted to ensure different REE speciation configurations, as presented in the first part of the results section. The experimental conditions were the same as those used by Marsac et al. (2012) who investigated REE-Al competition for HA binding, Al was replaced by Fe, namely: (i) $\Sigma[\mathrm{REE}]=[\mathrm{Fe}]=10 \mu \mathrm{M}$, (ii) $[\mathrm{HA}]=6.7 \mathrm{mg} \mathrm{L}^{-1}$ of carbon (i.e. REE/HA $=210^{-2} \mathrm{molREE} / \mathrm{molC}$ ), and (iii) ionic strength equal to $0.01 \mathrm{M}(\mathrm{NaCl}) . \Sigma[\mathrm{REE}]=10 \mu \mathrm{M}$ corresponds to $110 \mu \mathrm{g} \mathrm{L}^{-1}$ of each REE, i.e. from $7.910^{-7} \mathrm{M}$ to $6.310^{-7} \mathrm{M}$ for $\mathrm{La}$ and $\mathrm{Lu}$, respectively. From nitrate standards solutions, the fourteen REE and Fe were simultaneously added to $50 \mathrm{~mL}$ HA suspensions with $10^{-2} \mathrm{M} \mathrm{NaCl}$ electrolyte solutions. The $\mathrm{pH}$ was varied from 3 to 6 because for $\mathrm{pH}>6$, REE are strongly bound to HA (>99\%) and REE concentrations in fraction $<5 \mathrm{KDa}$ could not be detected by ICP-MS.

The experimental solutions were stirred for $48 \mathrm{~h}$ to reach equilibrium according to the protocol defined by Pourret et al. (2007b). The pH was regularly monitored with a combined Radiometer Red Rod electrode, calibrated with WTW standard solutions ( $\mathrm{pH} 4$ and 7). The accuracy of the $\mathrm{pH}$ measurements was $\pm 0.05 \mathrm{pH}$ units. At equilibrium $(48 \mathrm{~h}), 10 \mathrm{~mL}$ of the suspension were sampled and ultra-filtered at $5 \mathrm{kDa}$ to separate the REE-HA and Fe-HA complexes from the remaining inorganic REE and Fe. Ultrafiltrations were carried out by centrifuging the solution aliquots through $15 \mathrm{~mL}$ centrifugal tubes equipped with permeable 
membranes of $5 \mathrm{kDa}$ pore size (Vivaspin 15RH12, Sartorius). All of the membranes used were first washed with $0.15 \mathrm{~mol} \mathrm{~L}^{-1} \mathrm{HCl}$, then rinsed twice with ultrapure water to minimize contamination. Centrifugations were performed using a Jouan G4.12 centrifuge with swinging bucket rotor at $3000 \mathrm{~g}$ for 30 minutes. The removal of HA fractions $<10 \mathrm{kDa}$ in the HA pristine solution ensures that no organic molecules pass through the $5 \mathrm{kDa}$ membrane at this stage of the experiments. All experiments were performed in triplicate.

The new experimental results were compared with experimental data published earlier by Marsac et al. (2012) for REE binding by HA without Fe competition, which provided the Fefree experiments. Speciation calculations carried out with PHREEQC demonstrated that all of the inorganic REE could be confidently assumed to be free aqueous $\mathrm{REE}^{3+}$, and could thus be modeled accordingly (Tang and Johannesson, 2003; Pourret et al., 2007b; Marsac et al., 2010). The control of $\mathrm{Fe}^{3+}$ activity by the precipitation of $\mathrm{Fe}(\mathrm{OH})_{3}$ is described by the following reaction:

$$
\mathrm{Fe}(\mathrm{OH})_{3}+3 \mathrm{H}^{+}=\mathrm{Fe}^{3+}+3 \mathrm{H}_{2} \mathrm{O} \quad \mathrm{K}_{\mathrm{S}}
$$

Figure 1 presents the $\mathrm{Fe}$ speciation for $[\mathrm{Fe}]=10 \mu \mathrm{M}$ in $0.01 \mathrm{M} \mathrm{NaCl}$ aqueous solution calculated with PHREEQC. Fe hydrolysis constants were taken from Milne et al. (2003), whereas $\log \mathrm{K}_{\mathrm{S}}$ was set equal to 5 , which simulates the precipitation of poorly crystalline $\mathrm{Fe}$ (hydr)oxides (IUPAQ Stability Constants Database). In contrast to REE, calculations performed for Fe reveal a more complex speciation, with the concomitant occurrence of the $\mathrm{Fe}^{3+}, \mathrm{FeOH}^{2+}$ and $\mathrm{Fe}(\mathrm{OH})_{2}{ }^{+}$species depending on the $\mathrm{pH}$ and the precipitation of $\mathrm{Fe}(\mathrm{OH})_{3}$ starting from $\mathrm{pH} 3.5$.

The REE complexation with HA is described using the apparent partition coefficient $\mathrm{K}_{\mathrm{d}}$ (in $\mathrm{mL} \mathrm{g}^{-1}$ ), as follows:

$$
\mathrm{K}_{\mathrm{d}}\left(\operatorname{Ln}_{\mathrm{i}}\right)=\left(\frac{\left[\mathrm{Ln}_{\mathrm{i}}\right]_{\text {tot }}}{\left[\mathrm{Ln}_{\mathrm{i}}\right]_{\mathrm{aq}}}-1\right) / \mathrm{DOC}
$$


where $\mathrm{Ln}_{\mathrm{i}}=\mathrm{La}$ to $\mathrm{Lu}$, "tot" and "aq" refer to the total amount of the REE initially introduced and the aqueous REE in the filtrate $(<5 \mathrm{kDa})$, respectively.

\subsection{Solution analysis}

Rare earth elements and Fe concentrations $\left([\mathrm{Fe}]>30 \mu \mathrm{g} . \mathrm{L}^{-1}\right)$ were determined with an Agilent Technologies TM HP4500 ICP-MS instrument. Ultrafiltrates, containing Fe and REE inorganic species, were directly injected after adding $\mathrm{HNO}_{3}$ to a concentration of $0.37 \mathrm{~N}$. The initial suspensions were also analyzed to precisely determine the total amounts of REE and Fe processed in each experiment. The suspensions were first digested with sub-boiled nitric acid $\left(14 \mathrm{~N} \mathrm{HNO}_{3}\right)$ at $100^{\circ} \mathrm{C}$, and then resolubilized in $0.37 \mathrm{~N} \mathrm{HNO}_{3}$ after complete evaporation, to avoid interferences with organic carbon during mass analysis by ICP-MS. Quantitative analyses were performed using a conventional external calibration procedure. Three external standard solutions with REE and Fe concentrations similar to the analyzed samples were prepared from a multi-REE and a Fe standard solution (Accu Trace ${ }^{\mathrm{TM}}$ Reference, $10 \mathrm{mg} \mathrm{L}^{-1}$, USA). Indium was added to all samples as an internal standard at a concentration of 0.87 $\mu \mathrm{mol} \mathrm{L} \mathrm{L}^{-1}(100 \mathrm{ppb})$ to correct for instrumental drift and possible matrix effects. Indium was also added to the external standard solutions. Calibration curves were calculated from the measured REE/indium and Fe/indium intensity ratios. As established from repeated analyses of the multi-REE standard solution (Accu Trace ${ }^{\mathrm{TM}}$ Reference, USA) and SLRS-4 water standard, the instrumental error on the REE and Fe analysis are below 3 and 5\%, respectively. Iron concentrations $<30 \mu \mathrm{g} \cdot \mathrm{L}^{-1}$ were determined using a furnace atomic absorption spectrometer (SOLAAR M6, THERMO).

Dissolved organic carbon concentrations were determined using a Shimadzu 5000 TOC analyzer. The accuracy of the DOC concentration measurements is estimated at $\pm 5 \%$, as determined by repeated analysis of freshly prepared standard solutions (potassium biphtalate). 


\subsection{PHREEQC/Model VI}

Humic Ion-Binding Model VI was developed by Tipping (1998) and is implemented in the geochemical program WHAM 6. Model VI equations were recently introduced into PHREEQC (version 2) developed by Parkhurst and Appelo (1999) for the whole REE group (Marsac et al., 2011). PHREEQC is a computer code based on an ion-association aqueous model, which was designed to perform speciation and saturation-index calculations in water. PHREEQC/Model VI coupling allowed the REE-HA binding description to be improved, notably by removing the linear relationship imposed by Model VI between the carboxylicand phenolic-cation binding parameters, and by imposing new constraints (see Marsac et al., 2011 for more details).

In Model VI and PHREEQC/Model VI, HA are described as discrete acido-basic chemical functional groups (carboxylic and phenolic) able to bind aqueous metal ions (e.g. $\mathrm{La}^{3+}$ or $\mathrm{Fe}^{3+}$ ) and their first hydrolysis products (e.g. $\mathrm{LaOH}^{2+}$ or $\mathrm{FeOH}^{2+}$ ), forming either monodentate, bidentate or tridentate complexes. HA site density is defined by the parameter $\mathrm{n}_{\mathrm{A}}$, in mol g $\mathrm{g}^{-1}$. There are $\mathrm{n}_{\mathrm{A}}$ type A sites (i.e. carboxylic) and $\mathrm{n}_{\mathrm{A}} / 2$ type $\mathrm{B}$ sites (i.e. phenolic). In practice, thanks to Tipping's (1998) work, cation stability constants are adjusted using two parameters, $\log \mathrm{K}_{\mathrm{MA}}$ and $\log \mathrm{K}_{\mathrm{MB}}$, for the carboxylic and phenolic groups, respectively. Another parameter $\left(\Delta \mathrm{LK}_{2}\right)$ is introduced to increase the cation stability constants with a fraction of the multidentate sites, by considering them as chelate ligands or ligands involving additional chemical groups, such as nitrogen containing groups. To accurately simulate REEHA binding, Marsac et al. (2011) demonstrated that the $\Delta \mathrm{LK}_{2}$ parameter had to be optimized independently for the carboxylic $\left(\Delta \mathrm{LK}_{2 \mathrm{C}}\right)$ and phenolic groups $\left(\Delta \mathrm{LK}_{2 \mathrm{P}}\right), \Delta \mathrm{LK}_{2}$ value for carboxy-phenolic groups being a weighted average of $\Delta \mathrm{LK}_{2 \mathrm{C}}$ and $\Delta \mathrm{LK}_{2 \mathrm{P}}$ (depending on the amount of carboxylic and phenolic groups constituting the multidentate sites). In the present study, the binding of Fe polymers to HA was defined to be consistent with the spectroscopic 
results of Vilgé-Ritter et al. (1999), Gustafsson et al. (2007) and Karlsson and Persson (2010). A preliminary sensitivity study showed that the best fit was achieved by introducing $\mathrm{Fe}$ trimers in the calculations (i.e. $\mathrm{Fe}_{3} \mathrm{O}_{2}{ }^{5+}$ ). Chemical reactions were written as follow in PHREEQC/Model VI:

$\mathrm{HA}-\mathrm{S}^{-\mathrm{n}}+3 \mathrm{Fe}^{+3}+2 \mathrm{H}_{2} \mathrm{O}=\mathrm{HA}-\mathrm{S}-\mathrm{Fe}_{3} \mathrm{O}_{2}{ }^{(5-\mathrm{n})}+4 \mathrm{H}^{+}$

where HA-S ${ }^{-n}$ represents one HA site (mono-, bi- or tridentate). To calculate the formation constants, the Model VI relationship between parameters was used.

An electrical double layer, where only counter-ions can accumulate, is also defined in the model. The double layer thickness is set by the Debye-Hückel parameter $\kappa=\left(3.29 \times 10^{9} \mathrm{x}\right.$ $\left.\mathrm{I}^{1 / 2}\right)^{-1}$ (Appelo and Postma, 2005). The distribution of ions between the diffuse layer and the bulk solution is calculated by a simple Donnan model. The intrinsic equilibrium constants are corrected by the Boltzmann factor that depends on the HA surface area, which was determined to be equal to 19000 and $15000 \mathrm{~m}^{2} / \mathrm{g}$ at an ionic strength of 0.01 and $0.7 \mathrm{M}$, respectively (Marsac et al., 2011).

Errors between the experiments and simulations were quantified by the root mean square error of the regression (RMSE), i.e. the sum of the squares of the differences between the observed and calculated $\log v$, where $v$ is the amount of REE bound to HA per gram of dissolved organic carbon (DOC). The goodness-of-fit measure was considered to be of good quality if two conditions were fulfilled: (i) the total RMSE calculated from the whole experimental conditions and REE must be low, and (ii) the RMSE values calculated for the fourteen REE must be sufficiently close to each other. 


\section{Results}

\subsection{Primary consideration from modeling}

Under the present experimental conditions, PHREEQC/Model VI calculations show that at pH 3, REE are mainly bound to carboxylic sites and to the few strong multidentate sites, whereas at $\mathrm{pH} 6$, REE are partitioned between the carboxylic and phenolic sites that encompass both carboxy-phenolic and phenolic sites. Figure 2 illustrates the quantitative distribution of the REE among the different HA sites under both $\mathrm{pH}$ conditions. At $\mathrm{pH} 3$, up to $97 \%$ of $\mathrm{La}$ is bound to carboxylic sites compared to $50 \%$ for $\mathrm{Lu}$. The remaining $50 \%$ of $\mathrm{Lu}$ is complexed to strong multidentate sites (which can be carboxylic, phenolic or carboxyphenolic). At pH 6, more REE are bound to HA because of the lower competition of protons. Because the REE concentrations are higher than the number of strong multidentate sites, the strong multidentate sites can be neglected in the REE repartition description. Part of the phenolic sites are deprotonated and are thus more active for REE binding. Seventy percent of the $\mathrm{Lu}$ was, therefore, bound to phenolic sites. At $\mathrm{pH} \mathrm{6,} \mathrm{La} \mathrm{remained} \mathrm{essentially} \mathrm{bound} \mathrm{to}$ carboxylic sites (ca. 80\%). According to the experimental conditions and modeling calculations (Figure 1), Fe competition should result in the following $\log \mathrm{K}_{\mathrm{d}}{ }^{\mathrm{REE}}$ pattern: (i) a preferential LREE decrease at $\mathrm{pH} 3$ and 6, if $\mathrm{Fe}$ is preferentially bound to carboxylic sites at any $\mathrm{pH}$, and (ii) a preferential HREE decrease at $\mathrm{pH}=3$ and 6 , if $\mathrm{Fe}$ is preferentially bound to strong multidendate or phenolic (sensu-lato) sites depending on $\mathrm{pH}$.

In the present experiments, $\mathrm{Fe}$ may precipitate as $\mathrm{Fe}(\mathrm{OH})_{3}$, especially at $\mathrm{pH}=6$, and therefore sorb REE. Quinn et al. (2006), who studied REE sorption to Fe hydroxides, proposed numerical equations to calculate the amount of sorbed REE. By applying their model, we calculated the REE partition coefficient for the $\mathrm{REE} / \mathrm{Fe}(\mathrm{OH})_{3}$ system $\left(\mathrm{K}_{\mathrm{d}}^{\mathrm{REE}}(\mathrm{Fe})\right)$, that is, at our experimental conditions, but without HA. Knowing the $\mathrm{K}_{\mathrm{d}}{ }^{\mathrm{REE}}(\mathrm{HA})$ in the REE-HA 
system, we estimated that REE sorption to $\mathrm{Fe}(\mathrm{OH})_{3}$ was $<1 \%$ in the REE-Fe-HA system. Moreover, $\mathrm{Fe}$ binding to $\mathrm{HA}$ induces a decrease of the $\mathrm{Fe}(\mathrm{OH})_{3}$ precipitation and consequently of available $\mathrm{Fe}(\mathrm{OH})_{3}$ binding sites for REE. Therefore, REE sorption to $\mathrm{Fe}(\mathrm{OH})_{3}$ can reasonably be neglected at our experimental conditions.

\subsection{Experimental results}

The percentage of Eu bound to $\mathrm{HA}$ at $[\mathrm{Fe}]=0$ and $10 \mu \mathrm{M}$ is displayed in Figure 3. Without $\mathrm{Fe}$, approximately $30 \%$ of Eu is bound to $\mathrm{HA}$ at $\mathrm{pH} 3$; this amount reaches $95 \%$ at $\mathrm{pH}$. The presence of $\mathrm{Fe}$ in equal amounts to REE strongly decreases the REE binding by HA at $\mathrm{pH} 3$ because less than $10 \%$ of Eu is bound to HA. By contrast, at $\mathrm{pH} 6,90 \%$ of REE remain bound to HA. The iron competitive effect is less pronounced at $\mathrm{pH} 6$ because Fe hydroxide may precipitate at $\mathrm{pH}>4$. The decrease of REE bound to HA with Fe suggests that part of the Fe competes with REE for HA binding, even though some Fe likely precipitated as Fehydroxides at higher $\mathrm{pH}$.

The corresponding $\log \mathrm{K}_{\mathrm{d}}^{\mathrm{REE}}$ patterns are plotted for the REE-HA data of Marsac et al. (2012;

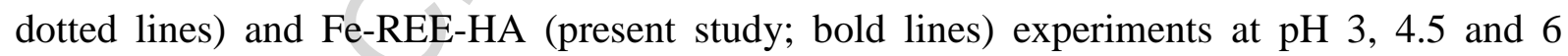
(Figure 4). For the REE-HA experiments, all patterns exhibit a MREE downward concavity, whatever the $\mathrm{pH}$. This feature is a classical feature of REE-HA binding experiments performed under high REE/HA conditions (Tang and Johannesson, 2003; Pourret et al., 2007b). At pH 3, the Fe competitive effect is effective for each REE, but the competition appears to be stronger for HREE than for LREE, as revealed by the $\log \mathrm{K}_{d}{ }^{\mathrm{REE}}$ pattern decrease for HREE. Iron is not only a strong competitor of the LREE that bind to HA carboxylic sites, but also competes with HREE that bind to the few HA multidendate sites. At pH 6, the competitive effect of Fe occurred with each REE, but the stronger competition with HREE was not observed anymore (parallel $\log \mathrm{K}_{d}^{\mathrm{REE}}$ patterns obtained with or without Fe) (Fig. 4). 
At $\mathrm{pH}=6, \mathrm{Fe}$ has thus equivalent affinity for HA carboxylic and phenolic sites than LREE and HREE.

\subsection{Data modeling}

Recent spectroscopic data has suggested that the amount of poly-Fe-HA complexes could be important at high Fe/HA conditions (Vilgé-Ritter et al., 1999; Gustafsson et al., 2007; Karlsson and Persson, 2010). A primary sensitivity study showed that the best fit was achieved by introducing the binding of $\mathrm{Fe}$ trimer $\left(\mathrm{Fe}_{3} \mathrm{O}_{2}{ }^{5+}\right)$ as a polymeric species into the model. First, the specific $\mathrm{HA}$ binding parameters of $\mathrm{Fe}^{3+} / \mathrm{FeOH}^{2+}$ were adjusted without considering the trimer. Second, $\mathrm{Fe}_{3} \mathrm{O}_{2}{ }^{5+}$ was considered in the simulation. Solubility products $(\log \mathrm{Ks})$ for ferrihydrite available in the literature range from 3 to 5 (Yu et al., 2002; Bonneville et al., 2004; Majzalan et al., 2004). Low solubility corresponds to aged and more crystalline ferrihydrite. The highest solubility corresponds to fresh ferrihydrite. Therefore, the $\mathrm{K}_{\mathrm{S}}$ value for $\mathrm{Fe}(\mathrm{OH})_{3}$ was considered to be an adjustable parameter. Two results are sought simultaneously in the modeling approach developed here, namely: (i) the model must reproduce the amount of $\mathrm{Fe}$ retained by the $5 \mathrm{kDa}$ ultrafiltration $(\mathrm{Fe}>5 \mathrm{kDa})$, and (ii) the model must also account for the competition observed between Fe and REE when bound to HA, especially through the observed REE-HA pattern.

The PHREEQC/Model VI Fe-HA binding parameters that give the best fit for the REE-FeHA competitive experiments are presented in Table 1. They are compared with Sm-HA and Lu-HA binding parameters which exhibit the highest binding parameters among REE, namely REE with the highest affinity for HA sites. Consistent with experimental observations, the comparison showed that $\mathrm{Fe}$ is a strong competitor of REE for all HA binding sites: log $\mathrm{K}_{\mathrm{MA}}\left(\mathrm{Fe}^{3+} / \mathrm{FeOH}_{2}^{+}\right)=3.5>\log \mathrm{K}_{\mathrm{MA}}\left(\mathrm{Sm}^{3+}\right)=3.4, \log \mathrm{K}_{\mathrm{MB}}\left(\mathrm{Fe}^{3+} / \mathrm{FeOH}^{2+}\right)=6.9>\log$ $\mathrm{K}_{\mathrm{MB}}\left(\mathrm{Lu}^{3+}\right)=5.2$ and $\Delta \mathrm{LK}_{2 \mathrm{C}}\left(\mathrm{Fe}^{3+}\right)=4>\Delta \mathrm{LK}_{2 \mathrm{C}}\left(\mathrm{Lu}^{3+}\right)=2.3$. Only $\Delta \mathrm{LK}_{2 \mathrm{P}}\left(\mathrm{Fe}^{3+}\right)=4$ was lower 
than $\Delta \mathrm{LK}_{2 \mathrm{P}}\left(\mathrm{Lu}^{3+}\right)=5.1$. However, the average $\Delta \mathrm{LK}_{2} \mathrm{Fe}^{3+}(=4)>\Delta \mathrm{LK}_{2} \mathrm{Lu}^{3+}(=3.7)$ suggests that $\mathrm{Fe}^{3+}$ has a stronger affinity for HA strong multidentate sites than $\mathrm{Lu}^{3+} . \Delta \mathrm{LK}_{2 \mathrm{C}}$ and $\Delta \mathrm{LK}_{2 \mathrm{P}}$ for $\mathrm{Fe}^{3+}$ were set equal because the experimental data did not allow these 2 parameters to be optimized separately. The $\Delta \mathrm{LK}_{2 \mathrm{C}}$ and $\Delta \mathrm{LK}_{2 \mathrm{P}}$ values for $\mathrm{FeOH}^{2+}$, as well as for the Fe trimer, were set equal to 0, because no stronger competition effect of Fe on HREE compared with LREE was observed in the experiments carried out at $\mathrm{pH}>4.5$ (see Figure 3). The $\mathrm{Fe}(\mathrm{OH})_{3}$ $\log \mathrm{K}_{\mathrm{S}}$ value was determined to equal 5.4, which is higher than the solubility of fresh ferrihydrite (i.e. 5). However, such a high value $\left(\log \mathrm{K}_{\mathrm{s}}=5.7\right)$ was already calculated for the $\mathrm{Fe}(\mathrm{OH})_{3}$ precipitated with HA (Weber et al., 2006). Therefore, the high binding capacity of HA can influence the crystallinity of the Fe hydroxides. The introduction of the Fe trimer in the simulations did not require any adjustment of $\log \mathrm{K}_{\mathrm{S}}$ and $\mathrm{Fe}^{3+} / \mathrm{FeOH}^{2+}$ binding to $\mathrm{HA}$ parameters.

Simulations with and without the Fe trimer are presented on Figure 3, as the percentage of REE bound to HA, and on Figure 5, as patterns of log $\mathrm{K}_{\mathrm{d}}$ REE-HA at $\mathrm{pH} 3$ and 6 . Both simulations are very similar and fit the experimental dataset reasonably well, especially the REE pattern $(\mathrm{RMSE}=0.08$ for all REE and both simulations). Simulation of the Fe-HA datasets from this study are presented on Figure 6 (Figure $6 \mathrm{a}, \mathrm{Fe} \%>5 \mathrm{kDa}$ ) as well as two simulations of the datasets provided by Liu and Millero (1999) (Figure 6 b and c). The Liu and Millero (1999) datasets determined the $\mathrm{Fe}$ solubility in $0.7 \mathrm{M} \mathrm{NaCl}$ with various concentrations of Aldrich $\mathrm{HA}$ at $\mathrm{pH} 8$ (Figure $6 \mathrm{~b}$ ) and in a $0.6 \mathrm{mg} \mathrm{L}^{-1} \mathrm{HA}$ concentration at various $\mathrm{pH}$ (Figure 6c). The introduction of the Fe trimer only improves the fit for the $\mathrm{Fe}$ REE competitive experiments. Without introducing the Fe trimer, the fit could be improved only if $\log \mathrm{K}_{\mathrm{MB}}\left(\mathrm{Fe}^{3+} / \mathrm{FeOH}^{2+}\right)$ was increased. However, this increase would have lead to a strong overestimation of the Fe-HA binding for the Liu and Millero (1999) datasets. Note that $\log \mathrm{K}_{\mathrm{s}}$ for $\mathrm{Fe}(\mathrm{OH})_{3}$ was set to 3.7 for Liu and Millero (1999) datasets, as determined by Milne 
et al. (2003). This value is probably due to an ionic strength effect $(0.7 \mathrm{M}$ vs $0.01 \mathrm{M}$ in the present experiments) as well as the equilibrium time (1 week vs $48 \mathrm{~h}$ in the present experiments).

Simulations with the newly optimized Fe-HA binding parameters in PHREEQC/Model VI were also performed for the experimental conditions used in the spectroscopy (EXAFS) study of Karlsson and Pearson (2010). They evidenced the formation of Fe polymers for Fe/HA = $50 \mathrm{mg} / \mathrm{g}$ and determined the proportion of Fe polymers relative to $\mathrm{pH}$. They demonstrated that Fe polymers represented 10 and $35 \%$ of the total $\mathrm{Fe}$ bound to $\mathrm{HA}$ at $\mathrm{pH} 4.2$ and 6.9, respectively. Conversely, no Fe polymers were detected in their experiments conducted at a lower $\mathrm{Fe} / \mathrm{HA}$ ratio (i.e. $5 \mathrm{mgFe} / \mathrm{gHA}$ ). Due to the large error on coordination numbers determined by EXAFS (20\%), these results are only qualitative, but they can be compared to the model simulations. PHREEQC/Model VI calculates a constant fraction of the Fe trimer complexed by HA between $\mathrm{pH}=4.2$ and 6.9 . For $\mathrm{Fe} / \mathrm{HA}=50 \mathrm{mg} / \mathrm{g}, 22 \%$ of the Fe calculated to be as Fe trimer-HA complexes, which is close to values determined by EXAFS. For Fe/HA $=5 \mathrm{mg} / \mathrm{g}$, no Fe trimer-HA complexes formation is determined. Therefore, the simulations considering the Fe trimer are relatively consistent with the spectroscopic observations.

\section{Discussion}

\subsection{Modeling Fe-HA interaction}

A major aim of the present study is to use modeling to study HA-Fe binding and the competitive effects of Fe on REE-HA complexation. The introduction of the Fe trimer in PHREEQC/Model VI allows the amount of poly-Fe-HA complexes consistent with spectroscopic observations to be calculated. However, the introduction of additional equations in a model increases its complexity. It should, therefore, significantly improve the experimental datasets fit as well as being statistically significant. Due to the large error of the 
coordination numbers determined by EXAFS, model and spectroscopy comparisons can only be qualitative. The simulations performed with and without the Fe polymers are quite similar. Only a slight fit improvement is obtained for Fe-HA binding datasets when Fe polymer was taken into account. Obviously, the relevance of introducing Fe polymers was not statistically justified. However, the complexation of polynuclear Fe species to HA might be an important mechanism because it might be considered as a first step to understand the formation of mixed Fe-organic matter colloids (e.g. Allard et al., 2004; Pédrot et al. 2012). Therefore, more quantitative experimental and spectroscopic Fe binding to HA studies are required to improve the model.

\subsection{Comparison between Al and Fe competitive effect on REE-HA binding}

The competition between REE and Al for HA binding was previously studied by Marsac et al., (2012). At $\mathrm{pH}=3$, such as $\mathrm{Fe}^{3+}, \mathrm{Al}^{3+}$ is a strong competitor of HREE which implies that $\mathrm{Al}^{3+}$ is preferentially bound to HA strong multidentate sites. However, the $\mathrm{Al}^{3+}$ competitive effect is less pronounced than $\mathrm{Fe}^{3+}$. This result is thermodynamically consistent because $\mathrm{Al}^{3+}$ generally has lower affinity for organic ligands than $\mathrm{Fe}^{3+}$ (e.g. in IUPAQ Stability Constant Database). At $\mathrm{pH}=6, \mathrm{Al}$ has a stronger competitive effect on REE-HA binding than $\mathrm{Fe}$, because the solubility of poorly-crystalline hydroxides for $\mathrm{Al}\left(\log \mathrm{K}_{\mathrm{s}}=9\right)$ is higher than for $\mathrm{Fe}\left(\log \mathrm{K}_{\mathrm{s}}=5\right)$. Therefore, at $\mathrm{pH}=6$ in the Al- system, there is a higher amount of REE competitive ions than in the Fe-system. Moreover, at $\mathrm{pH}=6, \mathrm{AlOH}^{2+}$ and $\mathrm{FeOH}^{2+}$ are the dominant species. The species show a contrasting HA binding behavior: $\mathrm{AlOH}^{2+}$ is a stronger competitor for LREE- than for HREE, whereas Fe shows the same competition effect for LREE and HREE. Aluminum thus has a higher affinity for HA carboxylic and phenolic groups than LREE and HREE, whereas it is equal for Fe. These findings are of particular importance in aquatic geochemistry because it shows that both 
elements can have contrasting effects on trace metals speciation in natural organic-rich waters. They also confirm that REE can be used as a reliable probe of cation-HA binding mechanisms.

\subsection{Impact of Fe and Al competition on REE patterns in natural organic-rich waters}

Humic substances control REE speciation in natural, organic-rich waters (Bidoglio et al., 1991; Takahashi et al., 1997; Viers et al., 1997; Dia et al., 2000; Johannesson et al., 2004; Gruau et al., 2004; Davranche et al., 2005; Pourret et al., 2007a; Pédrot et al., 2008). Variations in the binding capacity of humic acids, especially regarding the LREE/HREE ratio, are thus expected to result in variations in the REE patterns. Experimental data coupled with modeling identified at least three factors that can lead to such variations. The first factor is the REE/HA ratio or so-called metal loading (Yamamoto et al., 2010; Marsac et al. 2010). The metal loading may fractionate MREE and HREE. Under low metal loading conditions, HREE are preferentially bound to strong HA multidentate sites. Under high REE/HA conditions, MREE are preferentially bound to weak carboxylic HA sites. However, in contrast to laboratory experiments, in which the REE/HA ratio can vary from $10^{-4}$ to $10^{-2} \mathrm{~mol} \mathrm{REE} / \mathrm{mol}$ $\mathrm{C}$-, the REE/HA ratios are often very low in natural waters, ranging from $10^{-6}$ to $10^{-4} \mathrm{~mol}$ $\mathrm{REE} / \mathrm{mol} \mathrm{C}$ (Tang and Johannesson, 2010). In natural waters, the HA metal loading is, therefore, generally imposed by other dissolved metals, such as Fe and Al, which occur in much higher concentrations than REE. The occurrence of competitive dissolved metals is thus the second factor of REE pattern variations. Marsac et al. (2012) and the present study provide evidence that $\mathrm{Fe}$ and $\mathrm{Al}$ can compete with $\mathrm{REE}$ in terms of binding to HA. The third factor is the $\mathrm{pH}$, which controls the $\mathrm{Al}$ and $\mathrm{Fe}$ concentrations in solution and subsequently, the HA metal loading. Moreover, $\mathrm{pH}$ also controls $\mathrm{Al}$ and Fe speciation which, in turn, might induce variability in the REE pattern. This study demonstrates that $\mathrm{Fe}^{3+}$ competes more 
strongly with HREE than LREE, whereas Fe species formed at higher $\mathrm{pH}$ (i.e. $\mathrm{FeOH}^{2+}$ or $\mathrm{Fe}$ polymer) compete equally with LREE and HREE. $\mathrm{Al}^{3+}$ has the same competitive effect on REE-HA binding as $\mathrm{Fe}^{3+}$, but $\mathrm{AlOH}^{2+}$ competes mainly with LREE (Marsac et al., 2012). Ultimately, $\mathrm{pH}$ appears to be the key factor because the $\mathrm{pH}$ controls both the metal loading and the nature of $\mathrm{Al}$ and $\mathrm{Fe}$ species bound to $\mathrm{HA}$.

Because experimental conditions are often quite different from natural conditions, it seemed important to test the impact of the above three factors on solutions similar to natural waters. For this purpose, we used the World Average River Water (Table 11 in Tang and Johannesson, 2003) to simulate the effect of $\mathrm{pH}$ variability and $\mathrm{Al}$ and $\mathrm{Fe}$ competition on the $\log \mathrm{K}_{\mathrm{d}}^{\text {REE-HA }}$ pattern using PHREEQC/Model VI. It is important to note that several assumptions (as described below) imply that this study is purely qualitative. No predictions of REE speciation are discussed. Only $\log \mathrm{K}_{\mathrm{d}}^{\text {REE-HA }}$ pattern are used as an illustration of LREE and HREE relative affinity for $\mathrm{HA}$ in conditions similar to natural waters and, therefore, which REE are supposed to be enriched in these waters due to the presence of HA. As is classically done, we assumed that $20 \%$ of the active DOM $\left(=5 \mathrm{mg} \mathrm{L}^{-1}\right)$ present in World Average River Water is HA, and, therefore, introduced a concentration of $1 \mathrm{mg} \mathrm{L}^{-1}$ of $\mathrm{HA}$ in the model. The remaining $80 \%$ of DOM, representing fulvic acid (FA), was not taken into account because the REE-FA binding parameters for PHREEQC/Model VI were not yet determined. Although REE-FA and REE-HA should present different binding patterns, both patterns present comparable sensitivity to $\mathrm{pH}$, metal loading and cation competition. These results depend on the description of cations binding with HA and FA in Model VI (Tipping, 1998). Competition with $\mathrm{Ca}^{2+}$ and $\mathrm{Mg}^{2+}$ was also considered by introducing the HA binding constants determined by Tipping (1998) for these two cations in the PHREEQC/Model VI database. $\log \mathrm{K}_{\mathrm{S}}$ for $\mathrm{Al}(\mathrm{OH})_{3}$ and $\mathrm{Fe}(\mathrm{OH})_{3}$ were set equal to 9 and 5, respectively, which corresponds to poorly crystalline (hydr)oxide phases (IUPAC, Stability Constants Database). 
Two simulations were successively performed, with the $\mathrm{Al}$ and Fe concentrations both set equal to 0 , or equal to their concentrations in the World Average River Water. Calculations were performed from $\mathrm{pH} 4$ to 8 . The calculated $\log \mathrm{K}_{\mathrm{d}}^{\mathrm{REE}-\mathrm{HA}}$ patterns, normalized to La, are reported in Figure 7. Four points are underlined:

1) Without $\mathrm{Al}$ and $\mathrm{Fe}$ (Fig. 7a), the $\log \mathrm{K}_{\mathrm{d}}^{\text {REE-HA }}$ patterns show a systematic increase from $\mathrm{La}$ to $\mathrm{Lu}$, whatever the $\mathrm{pH}$. This continuous enrichment is a direct consequence of the low metal loading imposed by the low REE concentrations.

2) With both $\mathrm{Al}$ and $\mathrm{Fe}$ (Fig. 7b), the $\log \mathrm{K}_{\mathrm{d}}^{\mathrm{REE}-\mathrm{HA}}$ patterns show a decrease for HREE at $\mathrm{pH}$ 4. $\mathrm{Al}$ and $\mathrm{Fe}$ remain dissolved and impose a high metal loading. Therefore, $\mathrm{Al}^{3+}$ and $\mathrm{Fe}^{3+}$ compete strongly with HREE.

3) When the $\mathrm{pH}$ increases, the $\log \mathrm{K}_{\mathrm{d}}^{\mathrm{REE}-\mathrm{HA}}$ patterns show an increase in HREE induced by the metal loading decrease, which is itself involved in the precipitation of Fe and $\mathrm{Al}$ (hydr)oxides. At circumneutral $\mathrm{pH}$ (i.e. 6-8), $\mathrm{AlOH}^{2+}$ and $\mathrm{FeOH}^{2+}$ (or Fe polymers) are the dominant $\mathrm{Al}$ and $\mathrm{Fe}$ species bound to $\mathrm{HA}$ and are not able to suppress the log $\mathrm{K}_{\mathrm{d}}^{\text {REE-HA }}$ pattern increase. For $\mathrm{pH}$ between 6 and $8, \log \mathrm{K}_{\mathrm{d}}{ }^{\mathrm{REE}-\mathrm{HA}}$ patterns exhibit a HREE-HA binding decrease, compared with the simulation without $\mathrm{Al}$ and $\mathrm{Fe}$, due to the complexation of a small amount of $\mathrm{Al}^{3+}$ and $\mathrm{Fe}^{3+}$ to strong multidentate $\mathrm{HA}$ sites. At $\mathrm{pH} 7$ and 8, the $\log \mathrm{K}_{\mathrm{d}}^{\mathrm{REE}-\mathrm{HA}}$ patterns still increase from La to Lu.

4) In Figure 7 , the patterns of the $\mathrm{REECO}_{3}{ }^{+}$and $\mathrm{REE}(\mathrm{CO} 3)_{2}{ }^{-}$stability constants (log $\beta_{\mathrm{n}}{ }^{\text {REECO3 }}, \mathrm{n}=1$ or 2; Luo and Byrne, 2004) normalized to La are also reported. Note for the following discussion that the $\log \mathrm{K}_{\mathrm{d}}{ }^{\text {REE-HA }}$ patterns present a relative increase in HREE comparable to $\log \beta_{\mathrm{n}}{ }^{\mathrm{REECO} 3}$ between $\mathrm{pH} 7$ and 8 .

Organic-rich waters (DOC $>5 \mathrm{mg} \mathrm{L}^{-1}$ ) are generally classified into two groups, depending on their Upper Continental Crust (UCC)-normalized REE patterns: (i) acidic waters enriched in MREE, with $(\mathrm{La} / \mathrm{Yb})_{\mathrm{UCC}}$ close to 1 , and (ii) alkaline waters enriched in HREE, with 
$(\mathrm{La} / \mathrm{Yb})_{\mathrm{UCC}}<1$. This REE distribution pattern variation is often regarded as a REE speciation evolution. The MREE enriched patterns should correspond to waters in which REE are bound to DOM. By contrast, the HREE enriched patterns should correspond to waters in which REE are bound to carbonates (Elderfield et al., 1990; Tang and Johannesson, 2010). However, this REE pattern variation seems to be more akin to a continuous rather than a discontinuous phenomenon because the existence of two well-defined groups is not observed. Numerous organic-rich water samples (compiled by Marsac et al., 2010) exhibit a progressive $(\mathrm{La} / \mathrm{Yb})_{\mathrm{UCC}}$ decrease with increasing $\mathrm{pH}\left(\right.$ Fig. 8). This $(\mathrm{La} / \mathrm{Yb})_{\mathrm{UCC}}$ decrease indicates that the REE patterns vary from MREE-enriched patterns in acidic waters to strongly HREE-enriched patterns in circumneutral to basic waters. The above hypothesis based on the evolution of the REE speciation cannot explain this variability, which is more likely due to a competition effect between REE, Fe and Al with regards to their binding to DOM. Two arguments support this conclusion. The modeling calculations demonstrated that the REE speciation remained controlled by DOM up to $\mathrm{pH} 8$ (Pourret et al., 2007b). The marked HREE enrichment displayed at pH 6 to 8 might not result from a carbonate control of the REE speciation.

The second argument is provided by Figure 7 which shows the effects of $\mathrm{pH}$ and dissolved metal competition on the REE-HA binding. While remaining dominantly bound to DOM, REE are fractionated in organic waters. At low $\mathrm{pH}$, DOM preferentially binds MREE over HREE in response to $\mathrm{Al}$ and $\mathrm{Fe}$ competition with HREE. At high $\mathrm{pH}, \mathrm{DOM}$ preferentially binds HREE over LREE in response to the lower competition of $\mathrm{Al}$ and Fe with HREE.

\section{Conclusion}

Experiments were performed to investigate the competitive effect of Fe on REE binding to HA and, in turn, to identify the HA sites and the mechanisms involved in the Fe-HA binding. Different competitive effects of Fe on REE are observed depending on $\mathrm{pH}$. Under acidic 
conditions ( $\mathrm{pH}$ 3) and high metal loading, $\mathrm{Fe}^{3+}$, the major Fe species, competes more strongly with HREE than with LREE, suggesting a higher affinity of $\mathrm{Fe}^{3+}$ for the few strong multidentate HA sites. Under higher $\mathrm{pH}$ conditions (e.g. $\mathrm{pH}$ 6), Fe competes equally with both LREE and HREE, showing that Fe presents the same relative affinity for HA carboxylic and phenolic groups as LREE and HREE, respectively. The Fe-HA binding parameters in PHREEQC/Model VI were optimized to simulate both the Fe-HA binding and Fe competitive effects on REE. Two simulations were compared: the simulated binding of the default species used in Model VI $\left(\mathrm{Fe}^{3+}\right.$ and $\left.\mathrm{FeOH}^{2+}\right)$ with the simulated binding of a Fe polymer $\left(\mathrm{Fe}_{3} \mathrm{O}_{2}{ }^{5+}\right)$ as evidenced in a recent spectroscopy study in moderately acidic to neutral $\mathrm{pH}$ conditions. However, regarding the increasing complexity of the model with the introduction of additional Fe species binding to HA, this new mechanism was not statistically significant. To conclude, the present study provides fundamental knowledge on the Fe-REE competition mechanisms for HA binding and demonstrates that Fe can modify the REE-HA binding pattern. In turn, the ability of the REE to be used as a "speciation probe" to describe cation interactions with HA is verified once again, as previously shown for Al (Marsac et al., 2012). An alternative explanation for the variability in the REE patterns observed in natural, organicrich waters is also provided. So far, this variability has been regarded as being due to a REE speciation evolution, with the involvement of carbonate species at circumneutral to slightly alkaline waters. The present results combined with the previous data of Sonke and Salters (2005), Pourret et al. (2007a, b), Yamamoto et al. (2010), and Marsac et al. (2012) are more consistent with a hypothesis based on a continuous organic REE speciation coupled to a competition effect between REE, Fe and $\mathrm{Al}$ as regards their binding to DOM.

\section{Supporting informations}

Table with the experimental data presented in this article can be found in the online version. 


\section{Acknowledgments}

This research was funded by the French ANR, through the 'Programme Jeunes Chercheuses Jeunes Chercheurs' / 'SURFREE: Rare earth elements partitioning at solid-water interface: Impact on REE geochemical behaviour and tracing properties'. Dr. Sarah Mullin is acknowledged for post-editing the English style. 


\section{References}

Allard T., Menguy, N., J. Salomon, J., Calligaro, T., Weber, T., Calas, G., Benedetti, M. F., 2004. Revealing forms of iron in river-borne material from major tropical rivers of the Amazon Basin (Brazil). Geochim. Cosmochim. Acta 68, 3079-3094.

Appelo, C., Postma, D., 2005. Geochemistry, groundwater and pollution ( $2^{\text {nd }}$ edition). Taylor \& Francis, p. 595.

Auterives, C., 2007. Influence des flux d'eau souterraine entre une zone humide superficielle et un aquifère profond sur le fonctionnement hydrochimique des tourbières: exemple des marais du Cotentin, Basse-Normandie. Unpublished Ph.D. thesis, University of Rennes I, France. p. 261.

Bidoglio, G., Grenthe, I., Qi, P., Robouch, P., Omentto, N., 1991. Complexation of Eu and Tb with fulvic acids as studied by time-resolved laser-induced fluorescence. Talanta 38 (9), 999-1008.

Bonneville, S., Van Cappellen, P., Behrends, T., 2004. Microbial reduction of iron(III) oxyhydroxides: effect of mineral solubility and availability. Chem. Geol. 212, 255-268.

Davranche, M., Pourret, O., Gruau, G., Dia, A., Le Coz-Bouhnik, M., 2005. Adsorption of REE(III)-humate complexes onto $\mathrm{MnO}_{2}$ : experimental evidence for cerium anomaly and lanthanide tetrad effect suppression. Geochim. Cosmochim. Acta 69, 4825-4835.

Dia, A., Gruau, G., Olivié-Lauquet, G., Riou, C., Molénat, J., Curmi, P., 2000. The distribution of rare-earths in groundwater: assessing the role of source-rock composition, redox changes and colloidal particles. Geochim. Cosmochim. Acta 64, 4131-4151.

Dupré, L., Viers, J., Dandurand, J.-L., Polvé, M., Bénézeth, P., Vervier, P., Braun, J.-J., 1999. Major and trace elements associated with colloids in organic-rich river waters: Ultrafiltration of natural and spiked solutions. Chem. Geol. 160, 63-80. 
Elderfield, H., Upstill-Goddard, R., Sholkovitz, E.R., 1990. The rare earth elements in rivers, estuaries, and coastal seas and their significance to the composition of ocean waters. Geochim. Cosmochim. Acta 54, 971-991.

Gaillardet, J., Viers, J., Dupré, B., 2004. Elements in river waters. In Treatise on Geochemistry, vol. 5 (eds. E. D. Holland and K. K. Turekian). Elsevier-Pergamonm, pp. $225-263$.

Gruau, G., Dia, A., Olivié-Lauquet, G., Davranche, M., Pinay, G., 2004. Controls on the distribution of rare earth elements in shallow groundwaters. Wat. Res. 38, 3576-3586.

Gustafsson, J. P., Persson, I., Kleja, D. B., van Schaik, J. W. J., 2007. Binding of iron(III) to organic soils: EXAFS spectroscopy and chemical equilibrium modeling. Environ. Sci. Technol. 41, 1232-1237.

Henderson, P., 1984. Rare Earth Element Geochemistry, Elsevier, Amsterdam pp. 10-12.

Johannesson, K.H., Tang, J., Daniels, J.M., Bounds, W.J., Burdige, D.J., 2004. Rare earth element concentrations and speciation in organic rich blackwaters of the Great Dismal Swamp, Virginia, USA. Chem. Geol. 209, 271-294.

Karlsson, T., Persson, P., 2010. Coordination chemistry and hydrolysis of Fe(III) in a peat humic acid studies by X-ray absorption spectroscopy. Geochim. Cosmochim. Acta 74, 3040.

Lippold, H., Evans, N.D.M., Warwick, P., Kupsch, H. (2007) Competitive effect of iron(III) on metal complexation by humic substances: Characterization of ageing processes. Chemosphere 67, 1050-1056.

Liu, X., Millero, F. J., 1999. The solubility of iron hydroxide in sodium chloride solutions. Geochim. Cosmochim. Acta 63, 3487-3497.

Luo, Y. R., Byrne, R. H., 2004. Carbonate complexation of yttrium and the rare earth elements in natural waters. Geochim. Cosmochim. Acta 68, 691-699. 
Majzlan, J., Navrotsky, A., Schwertmann, U,. 2004. Thermodynamics of iron oxides: Part III. Enthalpies of formation and stability of ferrihydrite $\left(\mathrm{Fe}(\mathrm{OH})_{3}\right)$, schwertmannite $\left(\mathrm{FeO}(\mathrm{OH})_{3 / 4}(\mathrm{SO} 4)_{1 / 8}\right)$, and $\mathrm{Fe}_{2} \mathrm{O}_{3}$. Geochim. Cosmochim. Acta 68, 1049-1059.

Marsac, R., Davranche, M., Gruau, G., Dia, A., 2010. Metal loading effect on rare earth element binding to humic acid: Experimental and modelling evidence. Geochim. Cosmochim. Acta 74, 1749-1761.

Marsac, R., Davranche, M., Gruau, G., Bouhnik-Le Coz, M., Dia, A., 2011. An improved description of the interactions between rare earth elements and humic acids by modelling. Geochim. Cosmochim. Acta 75, 5625-5637.

Marsac, R., Davranche, M., Gruau, G., Dia, A., Bouhnik-Le Coz, M. 2012. Aluminium competitive effect on rare earth elements binding to humic acid. Geochim. Cosmochim. Acta 89, 1-9.

Milne, C.J, Kinniburgh, D.G., van Riemsdijk, W.H., Tipping, E., 2003. Generic NICADonnan model parameters for metal-ion binding by humic substances. Environ. Sci. Technol. 37, 958-971.

Olivié-Lauquet, G., Allard, T., Benedetti, M., Muller, J.-P. 1999. Chemical distribution of trivalent iron in riverine material from a tropical ecosystem: a quantitative EPR study. Wat. Res. 33, 2726-2734.

Parkhurst, D.L., Appelo, C.A.J., 1999. User's guide to PHREEQC (Version 2) - a computer program for speciation, batch reaction, one-dimensional transport and inverse geochemical calculation. Water-resources Investigation Report 99-4259, USGS, Denver, Colorado, p. 312.

Pédrot, M., Dia, A., Davranche, M., Bouhnik-Le Coz, M., Henin, O., Gruau, G., 2008. Insights into colloid-mediated trace element release at soil/water interface. J. Colloid Interface Sci. 325, 187-197. 
Pédrot, M., Le Boudec, A., Davranche, M., Dia, A., Henin, O., 2011. How does organic matter constrain Fe nano-particles nature, size and availability to biological reduction ? $J$. Colloid Interface Sci. 359, 75-85.

Pokrovsky, O.S., Dupré, B., Schott, J., 2005. Fe-Al-organic Colloids Control of Trace Elements in Peat Soil Solution: Results of Ultrafiltration and Dialysis. Aquat. Geochem. 11, 241-278.

Pokrovsky, O.S., Schott, J., Dupré, B., 2006. Trace element fractionation and transport in boreal rivers and soil porewaters of permafrost-dominated basaltic terrain in Central Siberia. Geochim. Cosmochim. Acta 70, 3239-3260.

Pourret, O., Davranche, M., Gruau, G., Dia, A., 2007a. Organic complexation of rare earth elements in natural waters: evaluating model calculations from ultrafiltration data. Geochim. Cosmochim. Acta 71, 2718-2735.

Pourret, O., Davranche, M., Gruau, G., Dia, A., 2007b. Rare earth complexation by humic acid. Chem. Geol. 243, 128-141.

Quinn, K. A., Byrne, R. H., Schijf, J., 2006. Sorption of yttrium and rare earth elements by amorphous ferric hydroxide: Influence of $\mathrm{pH}$ and ionic strength. Marine Chemistry 99, 128-150.

Sonke, J.E., Salters, V.J.M., 2006. Lanthanide-humic substances complexation. I. Experimental evidence for a lanthanide contraction effect. Geochim. Cosmochim. Acta 70, $1495-1506$.

Takahashi, Y., Minai, Y., Ambe, S., Makide, Y., Ambe, F., Tominaga, T., 1997. Simultaneous determination of stability constants of humate complexes with various metal ions using multitracer technique. The Science of the Total Environment 198, 61-71. 
Tang, J., Johannesson, K.H., 2003. Speciation of rare earth elements in natural terrestrial waters: assessing the role of dissolved organic matter from the modeling approach. Geochim. Cosmochim. Acta 67, 2321-2339.

Tang, J., Johannesson, K.H., 2010. Ligand extraction of rare earth elements from aquifer sediments: Implications for rare earth element complexation with organic matter in natural waters. Geochim. Cosmochim. Acta 74, 6690-6705.

Tanizaki, Y., Shimokawa, T., Nakamura, M., 1992. Physicochemical speciation of trace elements in river waters by size fractionation. Environ. Sci. Technol. 26, 1433-1444.

Tipping, E., 1998. Humic ion-binding model VI: an improved description of the interactions of protons and metal ions with humic substances. Aquatic Geochemistry 4, 3-48.

Tipping, E., Rey-Castro, C., Bryan, S. E., Hamilton-Taylor, J., 2002. Al(III) and Fe(III) binding by humic substances in freshwaters and implications for trace metal speciation. Geochim. Cosmochim. Acta 66, 3211-3224.

Tosiani, T., Loubet, M., Viers, J., Yanes, C., Dupré, B., Tapia, J., 2004. Major and trace elements in river borne materials from the Cuyuni Basin (Southern Venezuela): evidence for organo-colloidal control on the dissolved load and element redistribution between the dissolved load and the suspended load. Chem. Geol. 211, 305-334.

Vermeer, AW.P., Van Riemsdijk, W.H., Koopal, L.K., 1998. Adsorption of humic acid to mineral particles. 1. Specific and electrostatic interactions. Langmuir 14, 2810-2819.

Viers, J., Dupré, B., Polvé, M., Schott, J., Dandurand, J.-L., Braun, J.J., 1997. Chemical weathering in the drainage basin of a tropical watershed (Nsimi-Zoetele site, Cameroon): comparison between organic poor and organic-rich waters. Chem. Geol. 140, 181-206.

Vilgé-Ritter, A., Rose, J., Masion, A., Bottero, J.-Y., Lainé, J.-M., 1999. Chemistry and structure of aggregates formed with Fe-salts and natural organic matter. Colloids Surf. A: Physicochem. Eng. Aspects 147, 297-308. 
Weber, T., Allard, T., Tipping, E., Benedetti, M., 2006. Modelling Iron Binding to Organic Matter. Environ. Sci. Technol. 40, 7488-7493.

Yamamoto, Y., Takahashi, Y., Shimizu, H., 2010. Systematic change in relative stabilities of REE-humic complexes at various metal loading levels. Geochem. J. 44, 39-63.

Yu, J.-Y., Park, M., Kim, J., 2002. Solubilities of synthetic schwertmannite and ferrihydrite. Geochem. J. 36, 119-132. 


\section{Table and Figure Captions}

\section{Table 1}

Best estimates of $\log \mathrm{K}_{\mathrm{MA}}, \log \mathrm{K}_{\mathrm{MB}}, \Delta \mathrm{LK}_{2 \mathrm{C}}$ and $\Delta \mathrm{LK}_{2 \mathrm{P}}$ for $\mathrm{Fe}^{3+}$ and $\mathrm{Fe}_{3} \mathrm{O}^{5+}$ as determined by fitting the new Fe-REE-HA experimental data using PHREEQC/Model VI. Parameter values estimated previously by Marsac et al. (2011) for La, Sm, and Lu binding by HA are shown for comparison.

Fig. 1. Iron speciation calculated with PHREEQC for $[\mathrm{Fe}]=10 \mu \mathrm{M}$ in $0.01 \mathrm{M} \mathrm{NaCl}$ aqueous solution. $\log \mathrm{K}_{\mathrm{S}}$ for $\mathrm{Fe}(\mathrm{OH})_{3}$ is equal to 5 .

Fig. 2. Distribution of REE between the three major types of HA sites involved in REE binding. The calculated speciation only takes into account the amount of REE complexed to HA, and does not consider aqueous species. The simulations were performed at a high $\mathrm{REE} / \mathrm{HA}$ concentration ratio $\left(\Sigma[\mathrm{REE}]=10 \mu \mathrm{M},[\mathrm{DOC}]=6.7 \mathrm{mg} \mathrm{L}^{-1}\right)$, (a) at $\mathrm{pH}=3$ and (b) at $\mathrm{pH}=6$.

Fig. 3. Evolution of the percentage of Eu bound to $\mathrm{HA}$ with increasing $\mathrm{pH}$ for experiments conducted both with and without Fe addition (present study and Marsac et al. (2012), respectively). Error bars represent the standard deviations obtained from triplicate experiments. PHREEQC/Model VI modeling curves are also shown with and without the binding of the Fe trimer.

Fig. 4. Variations of the $\log \mathrm{K}_{\mathrm{d}}^{\mathrm{REE}}$ patterns depending on the $\mathrm{pH}$ and on the presence or lack of Fe in the HA-REE suspensions. Error bars represent the standard deviation from triplicate experiments. The experiments without Fe are from Marsac et al. (2012).

Fig. 5. Comparison between measured and modeled $\log \mathrm{K}_{\mathrm{d}}{ }^{\mathrm{REE}}$ patterns for the Fe-REE-HA competition experiments performed at $\mathrm{pH}=3$ and $6\left(\sum[\mathrm{REE}]=[\mathrm{Fe}]=10 \mu \mathrm{M},[\mathrm{HA}]=6.7 \mathrm{mg}\right.$ $\mathrm{L}^{-1}$ ), with and without the binding of the Fe trimer in the calculations.

Fig. 6. Comparison between the measured and modeled: (a) percentage of Fe present in the 5 $\mathrm{kDa}$ retentate in the Fe-REE-HA experiments relative to $\mathrm{pH}$ (present study), (b) $\mathrm{Fe}$ (III) 
solubility in $0.7 \mathrm{M} \mathrm{NaCl}$ solution at constant $\mathrm{pH}=8$ and variable HA concentration (Liu and Millero, 1998), (c) $\mathrm{Fe}$ (III) solubility in $0.7 \mathrm{M} \mathrm{NaCl}$ solution at constant HA concentrations (0 and $0.6 \mathrm{mg} \mathrm{L}^{-1}$ ) and variable $\mathrm{pH}$ (Liu and Millero, 1998). Simulations were performed with and without the binding of the Fe trimer to HA in the calculation.

Fig. 7. Simulated $\log \mathrm{K}_{\mathrm{d}}{ }^{\text {REE-HA }}$ patterns in the World Average River Water, depending on the $\mathrm{pH}$ and on the occurrence or lack thereof of a competition between $\mathrm{REE}, \mathrm{Fe}$ and $\mathrm{Al}$ for $\mathrm{HA}$ binding. Log $\mathrm{K}_{\mathrm{d}}{ }^{\mathrm{REE}}$ patterns have been normalized to La for convenience. Patterns for the REE stability constants $\left(\log \beta_{\mathrm{n}}{ }^{\mathrm{REECO} 3}\right)$ for the $\mathrm{REECO}_{3}{ }^{+}$and $\mathrm{REE}(\mathrm{CO} 3)_{2}{ }^{-}$species are shown for comparison (data from Liu and Byrne, 2004).

Fig. 8. Diagram illustrating the continuous decrease of $(\mathrm{La} / \mathrm{Yb})_{\mathrm{UCC}}$ with increasing $\mathrm{pH}$ in organic-rich waters (DOC > $5 \mathrm{mg} \mathrm{L}^{-1}$ ). Data source: Dia et al. (2000); Viers et al. (2000); Gaillardet et al. (2004); Gruau et al. (2004); Tosiani et al. (2004); Pokrovsky et al. (2006); Auterives (2007). UCC $=$ Upper Continental Crust. 


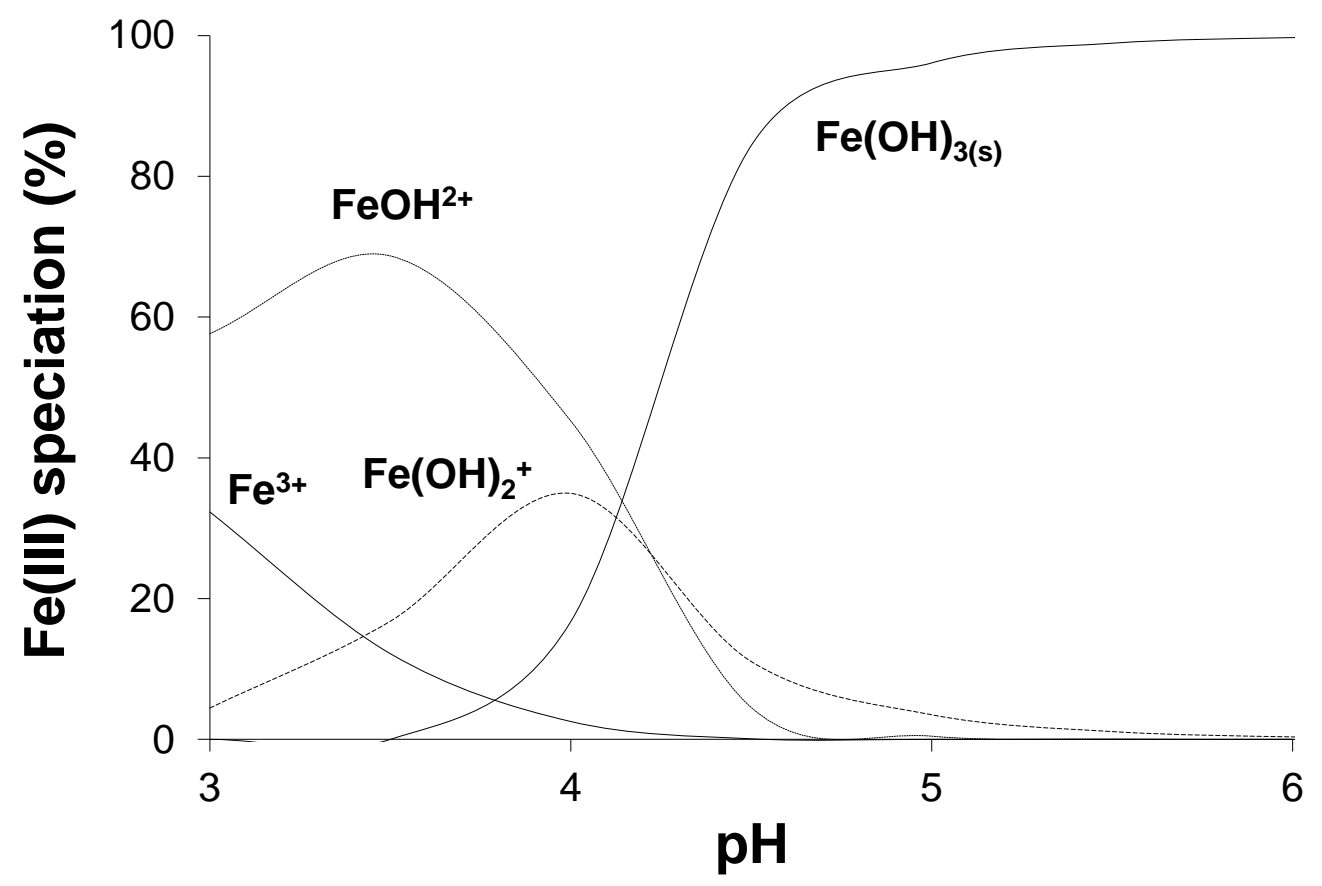

Figure 1 

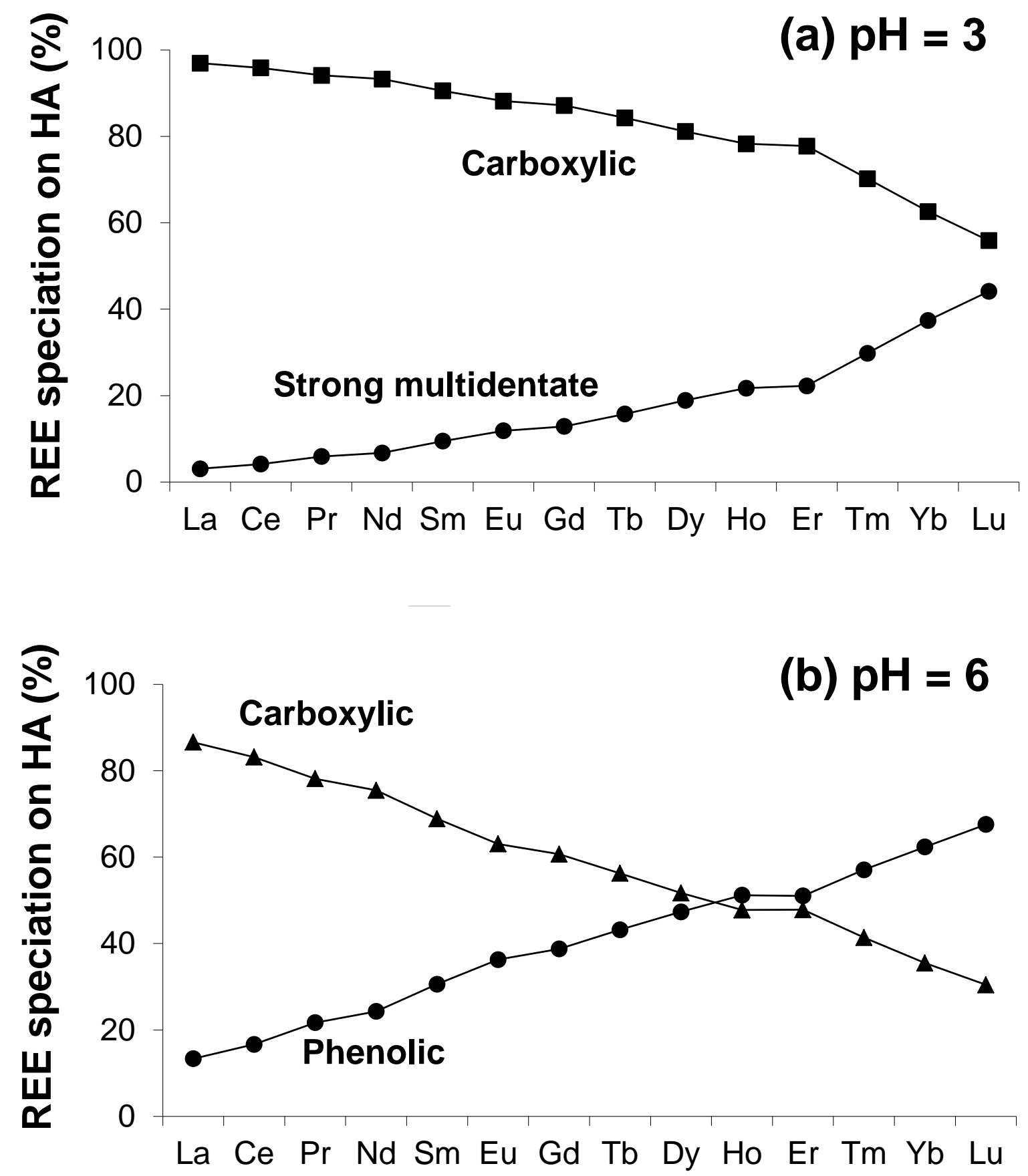

Figure 2 


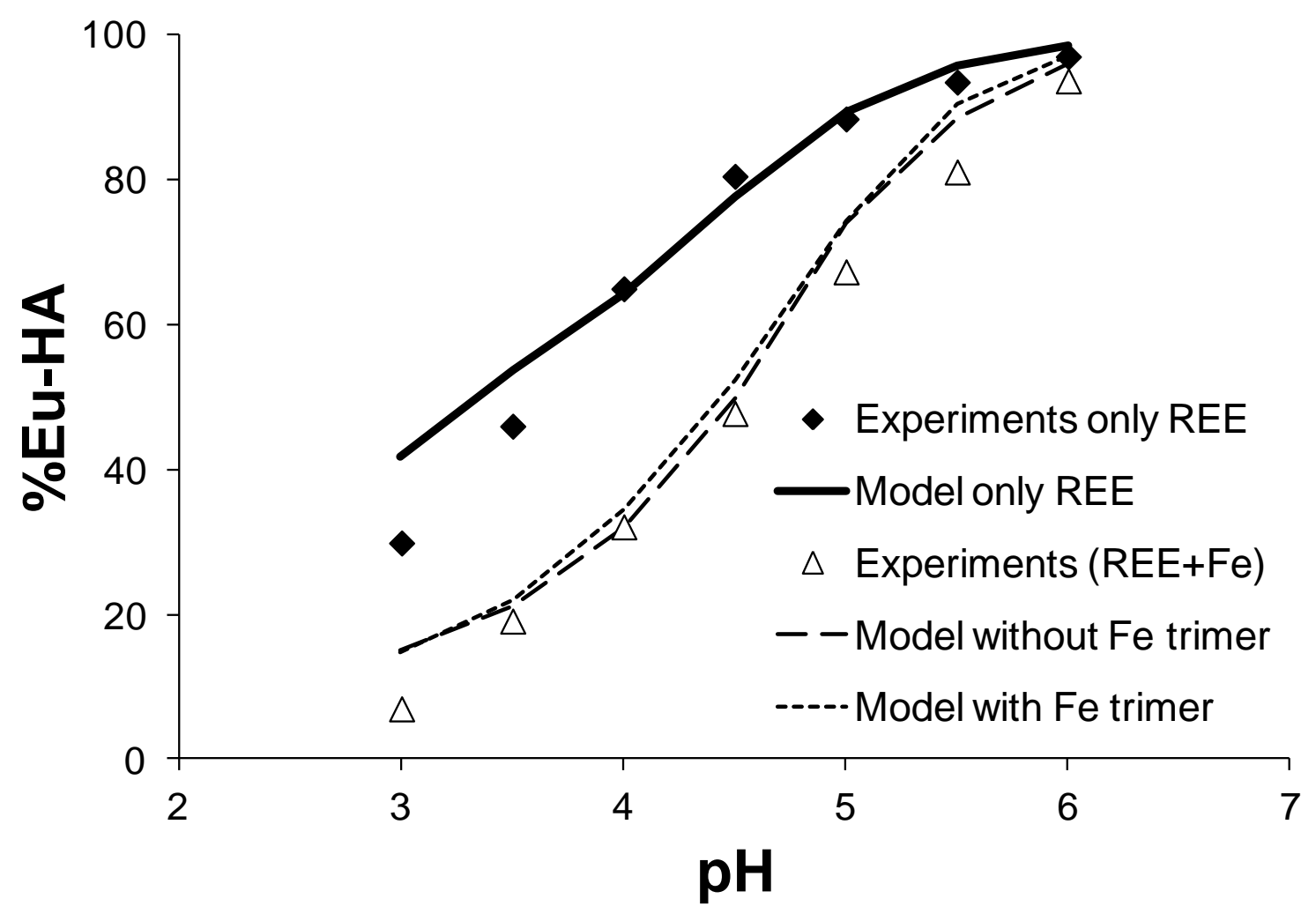

Figure 3 


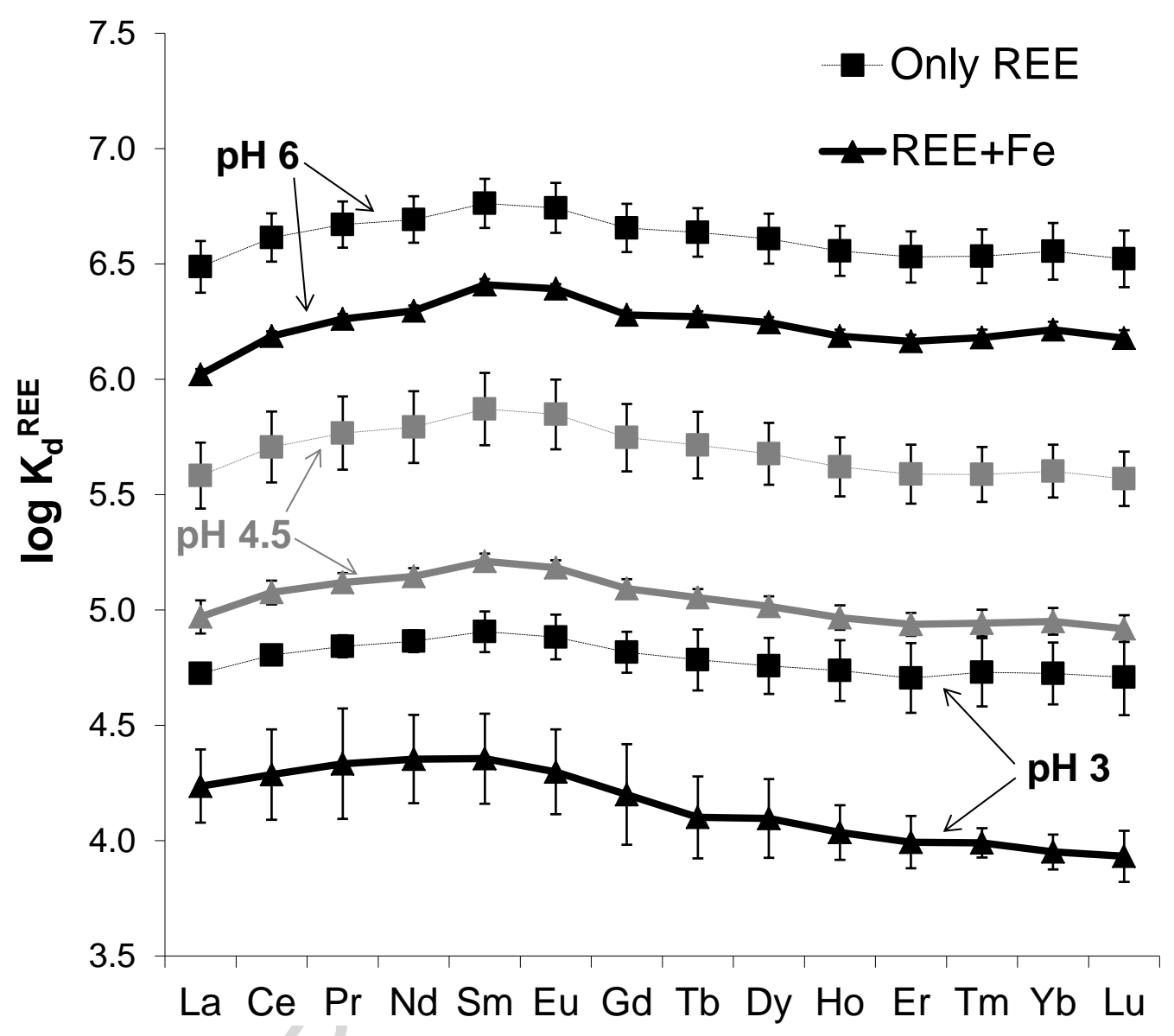

Figure 4 


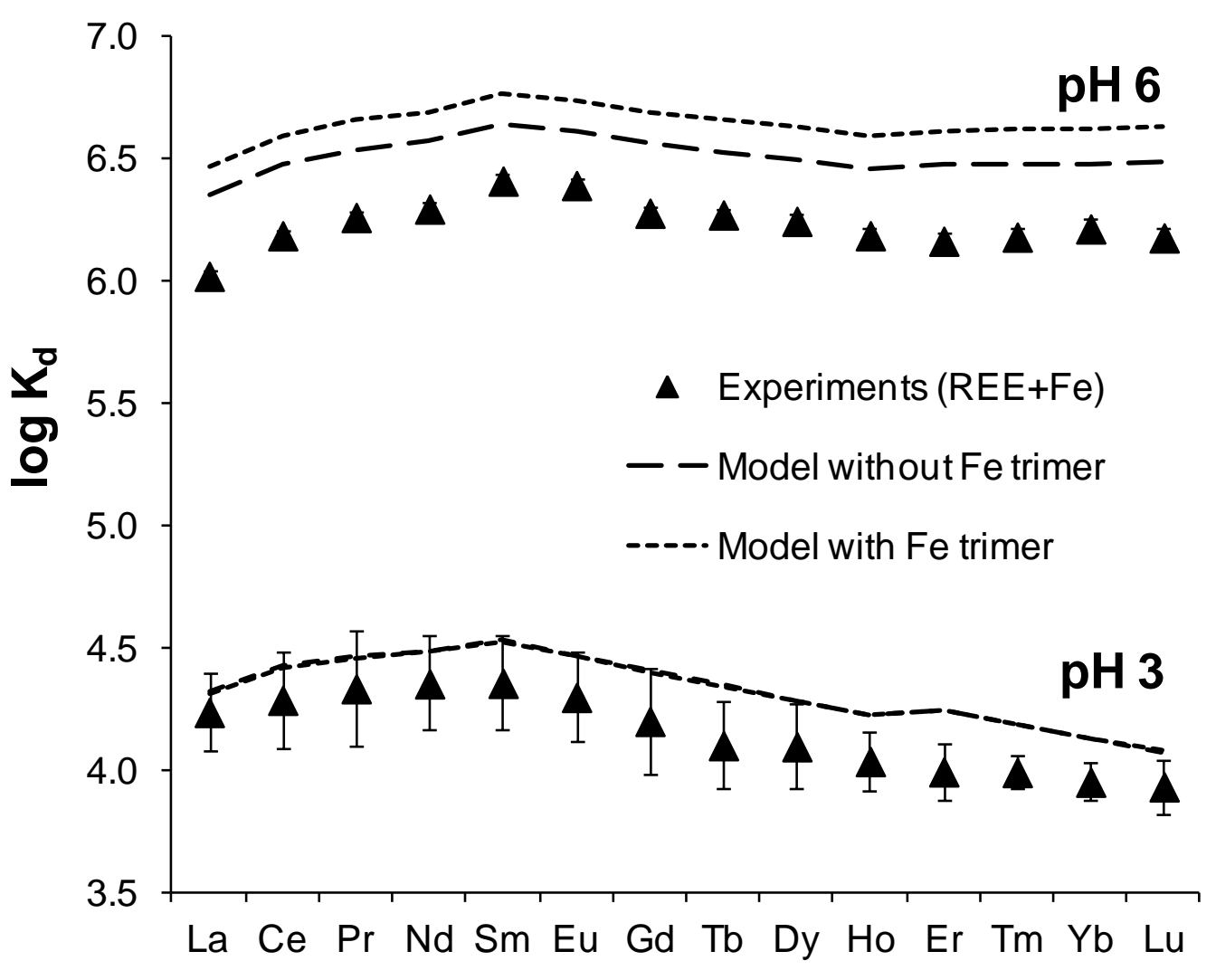

Figure 5 

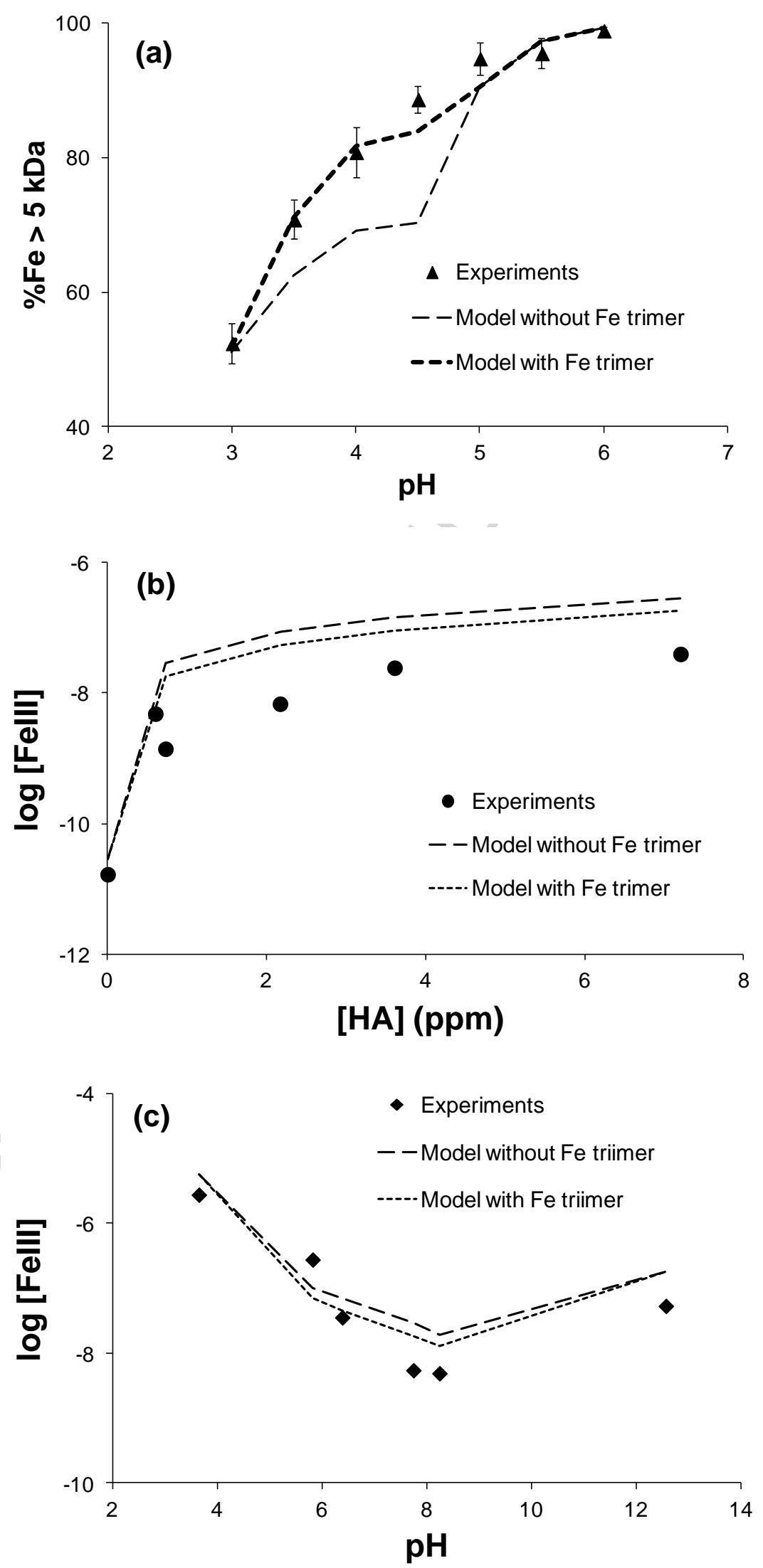

Figure 6 

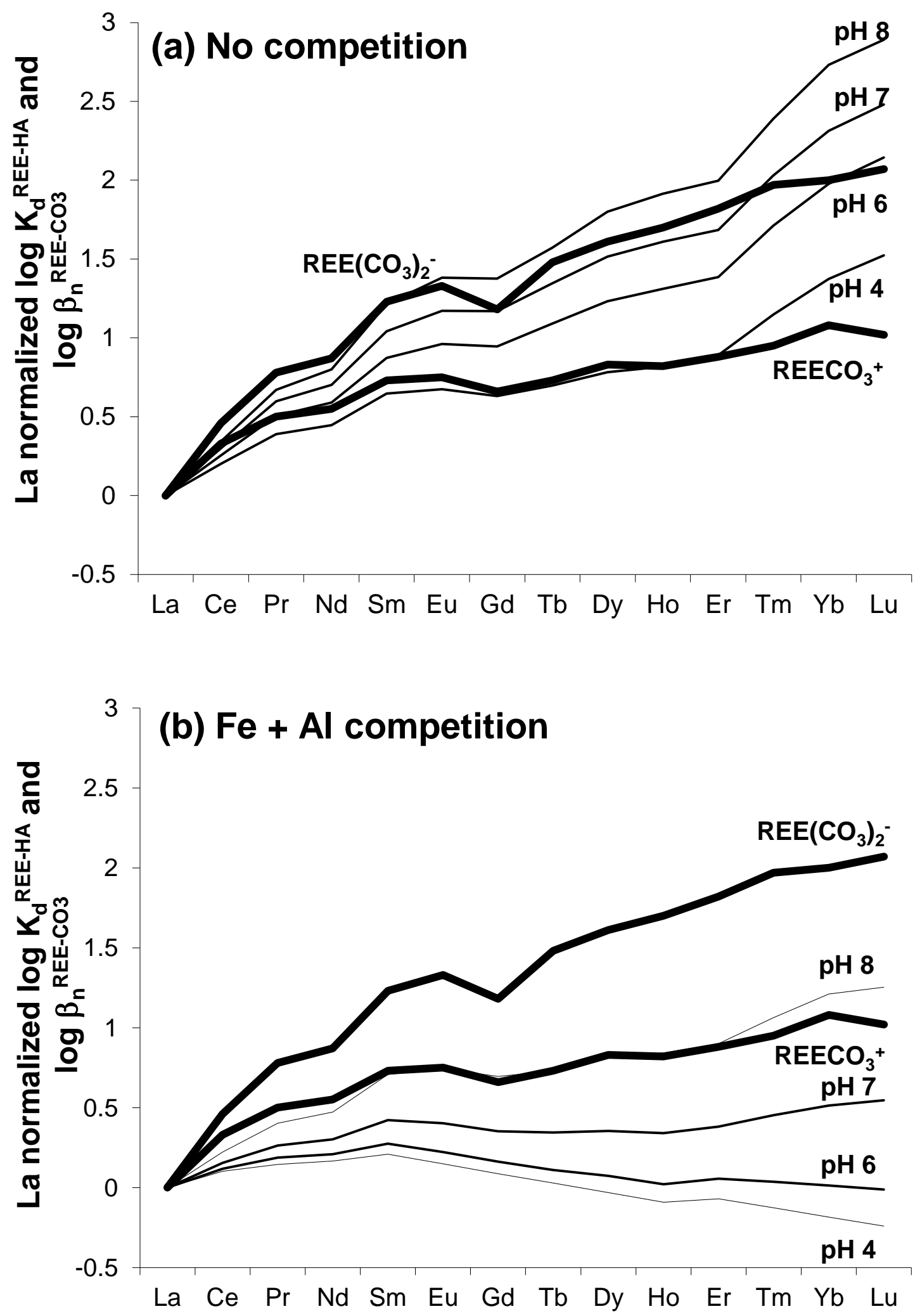

Figure 7 


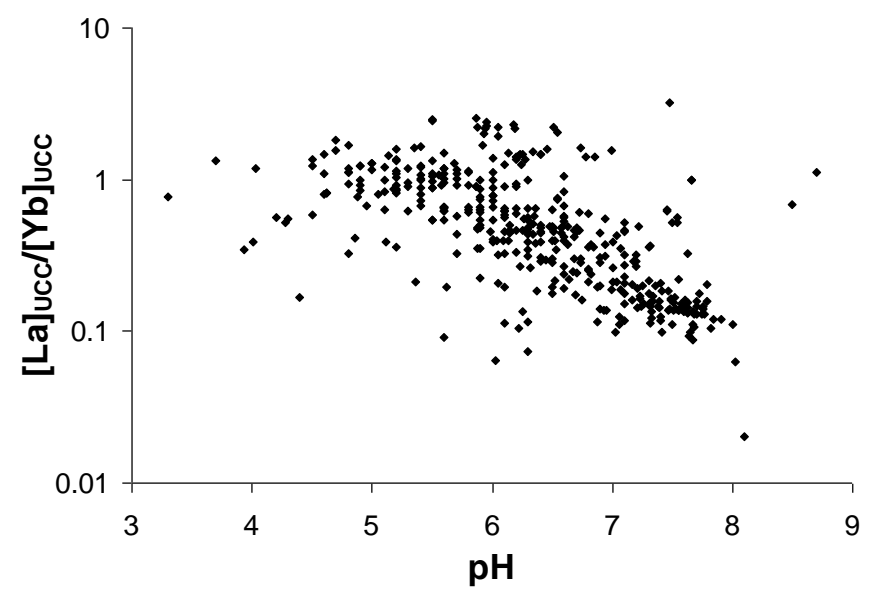

Figure 8 


\begin{tabular}{cccccc}
\hline Parameter & $\mathrm{Fe}^{3+} / \mathrm{FeOH}^{2+}$ & $\mathrm{Fe}_{3} \mathrm{O}^{5+}$ & $\mathrm{La}$ & $\mathrm{Sm}$ & $\mathrm{Lu}$ \\
\hline $\mathrm{Log} \mathrm{K}_{\mathrm{MA}}$ & 3.50 & 3.00 & 3.29 & 3.39 & 3.16 \\
$\log \mathrm{K}_{\mathrm{MB}}$ & 6.90 & 7.50 & 4.39 & 4.90 & 5.23 \\
$\Delta \mathrm{LK}_{2 \mathrm{C}}$ & $4.00^{*}$ & 0.00 & 2.01 & 2.09 & 2.31 \\
$\Delta \mathrm{LK}_{2 \mathrm{P}}$ & $4.00^{*}$ & 0.00 & 4.39 & 4.54 & 5.11 \\
\hline
\end{tabular}

Table 1 

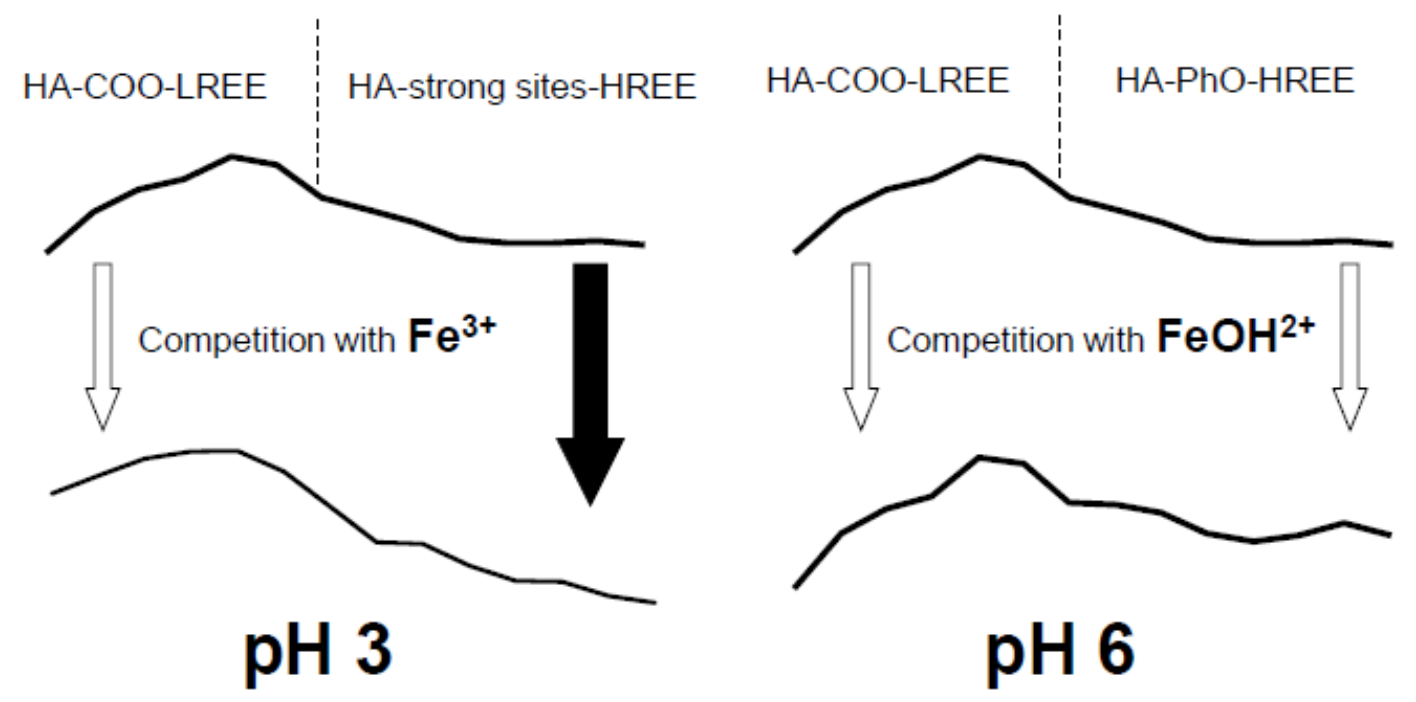

Graphical abstract 


\section{Highlights:}

- A study of the competitive complexation of Fe(III) and REE onto HA sites is proposed.

- REE and Fe binding were investigated using experiments and modeling.

- At acidic pH, Fe competes with heavy REE; at neutral pH, Fe competes for every REE

- Fe is bound to strong multidentate or carboxylic and phenolic sites relative to $\mathrm{pH}$.

- REE patterns on HA are controlled by metal loading, REE/cations competition and $\mathrm{pH}$. 